\title{
FIRST RUSSIAN CONFERENCE "GRAPHENE - MOLECULE AND 2D-CRYSTAL" (Novosibirsk, 8-12.09.2015)
}

\section{Vladimir I. Grachev}

Kotel'nikov Institute of Radio Engineering and Electronics, Russian Academy of Sciences, http://www.cplire.ru 11/7, Mokhovaya str., 125009 Moscow, Russian Federation

grachev@cplire.ru

Abstract. The information about the first Russian conference on graphene "Graphene - a molecule and 2D-crystal", held September 8-12, 2015 in Novosibirsk (Russia), which "grew" from the workshop of the same name, from 2013 held in Moscow under the leadership of S.P. Gubin is presented. Presented at the conference works conventionally been divided into five research areas: synthesis of graphene and related structures, theoretical methods attached to graphene materials, diagnostics of graphene and related structures, materials and devices based on graphene and related structures, hybrid materials based on carbon nanoparticles. The conference was attended by about 150 people from more than 20 institutes of the Russian Academy of Sciences and more than 10 universities in Russia and countries of near and far (the US, Britain, Germany, Japan, Kazakhstan, Belarus) countries. Having heard and discussed 50 reports and 60 posters. The conference was held in a warm atmosphere of the discussion on a high, according to the participants, the scientific level and with the universal desire to turn it into a permanent Russian conference on graphene.

Keywords: conference, graphene, molecules, crystals, synthesis, diagnostics, graphene structures, hybrid materials

PACS: 01.10.Fv, 51.05.ue

Bibliography -4 references

Received 20.11.2015

RENSIT, 2015, 7(2):108-130

DOI: $10.17725 /$ rensit.2015.07.108

CONTENTS

1. INTRODUCTION (108)

2. SyNTHESIS OF GRAPHENE AND RELATED STRUCTURES (110)

3. Theoretical methods and the diagnostics OF GRAPHENES (113)

\subsection{Poster Session (117)}

4. Materials and devices based on a Graphene (119)

4.1. Presentations of Sponsors (123)

5. Hybrid materials based oN CARbon NANOPARTICLES (123)

6. Closing of the conference (126)

REFERENCES (129)

\section{INTRODUCTION}

The first Russian conference on graphene, entitled "Graphene - a molecule and 2D-crystal" was conceived and initiated by well-known Russian specialist in nanochemistry - Professor Gubin Sergei Pavlovich, Dr Sci. Chem, USSR State Prize Laureate, Honored Scientist of Russia, head of the laboratory of chemistry of nanomaterials N.S. Kurnakov Institute of General and Inorganic Chemistry of Russian Academy of Sciences. S.P.
Gubin is already more than two years, led by Moscow, and from 2014 - Russian seminar of the same name based on the All-Russian Research Institute for Natural and synthetic diamonds and tools (VNIIAlmaz), a monthly gathering in Moscow at its meetings of 30-40 people.

The first conference, it was decided to carry out on the basis of the Siberian Branch of Russian Academy of Sciences, in Novosibirsk Akademgorodok (academcity). The ancient connections of Sergei Pavlovich with Siberia [see eg., 1] gived hope for the success of the planned business. The calculation was correct: the organization of the conference actively involved Nikolaev Institute of Inorganic Chemistry SB RAS in the face of its director Corresponding Member of Russian Academy of Sciences Vladimir Petrovich Fedin which supported the idea of conference, and who has really taken over the organization of the conference Head of the laboratory of physical chemistry of nanomaterials of this Institute Dr Sci. Phys\&Math, prof. Alexander Vladimirovich 
Okotrub. Soon, to the organization of the conference joined yet two institute SB RAS Rzhanov Institute of Semiconductor Physics and the Boreskov Institute of Catalysis SB RAS and Novosibirsk State University.

The Conference was supported by SB RAS, RFBR, financing participated personally S.P. Gubin, as well as NT-MDT Co. (Zelenograd), "Graphene Materials" (St.Petersburg), LLC AkKoLab (Moscow), CZL-laboratory equipment (Moscow), VNIIAlmaz (Moscow), Dia-M modern laboratory (Novosibirsk), VACOM (Germany), INUMiT (Lomonosov MSU, Moscow) - firms producing graphene and related equipment that S.P. Gubin and A.V. Okotrub managed to attract to participate in the conference for its exhibitions. The conference organizing committee, the core of which is composed of staff and postgraduates of A.V. Okotrub laboratory, headed by $\mathrm{PhD}$ Phys\&Math Y. Fedoseyeva and Dr Sci. Chem E.Yu. Buslaeva from Moscow IGIC RAS amounted database (more than 200 addresses) russian researchers in the field of graphene and related structures, as well as instruments and devices using graphene. First announcement of the conference with an invitation to participate was sent to the relevant e-mail addresses, as well as to leading academic secretaries of basic physical and chemical institutes of Russia in early November 2014, to the end of December was clear preliminary list of participants, the end of May had been received by the Organizing Committee more than 150 abstracts of participants who responded to the invitation, and had been finally agreed scientific conference program and its schedule.

The conference was held September 8-11, 2015 in the House of Scientists in Akademgorodok at the Marine Avenue, 23, a 10-minute walk from the hotel "Golden Valley" - the location of the participants. European level of the Small Hall and its interiors - a winter garden with fountains and aquariums, patio, art gallery, restaurant - lunch place for participants - maintain the tone of the working mood of its participants. In the bright and spacious lobby, an anticipating Small Hall, were organized the exhibitions sponsors of the conference and coffee breaks. In the continuation of the lobby, which served as a mezzanine of winter garden, were placed posters.

At the conference it was stated 150 people, the actual number of participants -117: 90 registered visitors and 20 from Novosibirsk participants, including five representing foreign countries - USA, UK, Japan, Kazakhstan and Belarus. In addition, regularly attended by about 30 unregistered users. Participants included members of research institutes of the Russian Academy of Sciences - IGIC, IBCP, ICHPH, IPCE, ICP, IPMT-HPM, GPI, JIHT, PTI, IMET, IRE, "Kurchatov Institute"; institutes SB RAS - NIIC, ISP, IC, IT, IUHM, IPPU, IBP, and Ural Branch IMP, IHT'T, IFTE; and universities - Lomonosov MSU, MIPT, MEPhI, MPEI, SPbU, Novosibirsk State University, SibFU, TSTU, CSU, NEFU, INP BSU. I.e. the participants came from Moscow, Chernogolovka, St. Petersburg, Ekaterinburg, Kurchatov, Novosibirsk, Krasnoyarsk, Tomsk, Omsk, Kemerovo, Yakutsk, Tambov, Minsk, Astana and from abroad. Small Hall of the House of Scientists with a capacity of 200 people was to filled every day by more than a hundred of participants [2].

The conference has been presented 20 plenary and 30 oral presentations lasting 30 and 20 minutes, respectively, and 60 works in the form of posters. Working language is Russian. The only report in English made by Professor Y. Kawazoe (Tohoku University, Sendai, Japan), which is a russian megagrant leader in the Institute of Thermal Physics SB RAS.

Presented at the conference works conventionally been divided into the following five research areas:

- Synthesis of graphene and related structures,

- Theoretical methods attached to graphene materials;

- Diagnostics of graphene and related structures,

- Materials and devices based on graphene and related structures,

- Hybrid materials based on carbon nanoparticles.

These areas do not exhaust the full scientific program of the conference, but they are advanced in this area. Conference was aimed at 
the development of new scientific approaches to problem-solving diagnostics and synthesis of graphene, the study of its physical and chemical properties, the problems of production and application of graphene in electronic devices, biomedical, electrochemical applications in catalysis, to problem-solving toxicity and ecology.

Information about the conference posted on the website of the Institute of Inorganic Chemistry SB RAS http://store.niic.nsc.ru/conferences/ graphene/, to its opening was issued a collection of abstracts, the opening of the conference was covered by local TV, and the entire course of its work - by video filming of moscow Center of science popularization (www.fundamentalscience. $\mathrm{ru}$ ) with the placement of material on video hosting You'Tube.

\section{DAY ONE. SYNTHESIS OF GRAPHENE AND RELATED STRUCTURES}

The conference opened on the sunny morning of September 8 in opening statement of its Chairman Professor Gubin S.P., in which he noted the response of the russian researchers on the convening of the conference, as well as non-standard decision of the Nobel Committee in 2010, which noted nonobvious to the scientific community of that time of the opening of the new allotrope of carbon is graphene; and the ongoing explosive growth of graphene publications, participation in the process of Russia and the objectives of this conference.

In his welcoming speech, Director of the Institute-organizer Dr Sci. Chem, prof., Corresponding Member of RAS V.P. Fedin noted the honor, rendered to his institution to take Russia's

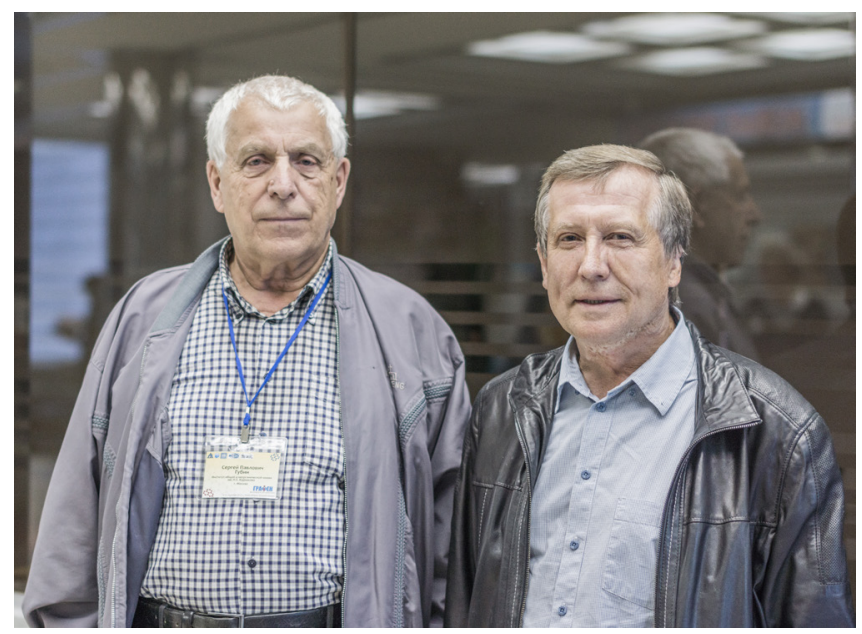

S.P. Gubin and V.P. Fedin

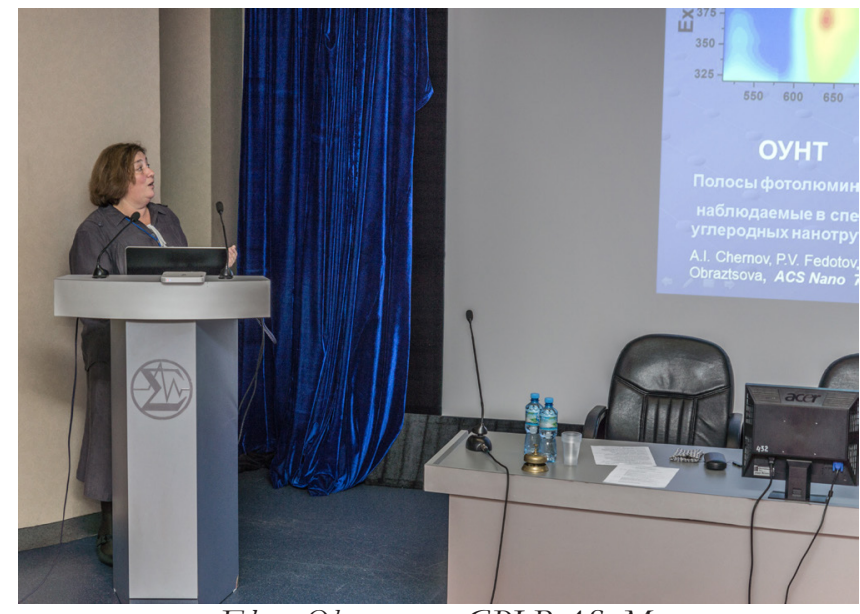

Elena Obraztsova, GPI RAS, Moscow

first conference on such breakthrough areas as Grafenika and wished conference fruitful work.

After the words of S.P. Gubin and V.P. Fedin Conference came into work mode: plenary session before lunch, and the breakout session after it. The first plenary session leads S.P. Gubin, opening program of conference with the presentation of PhD Phys\&Math Elena Obraztsova with colleagues from the moscow GPI, Boreskov IC SB RAS, and the Spanish firm (San Sebastian) about the transformation of stacks of coronen to the graphene stripes at temperatures of about $500^{\circ} \mathrm{C}$ in the filled coronene single-walled carbon nanotubes and photoluminescence of obtained onedimensional graphene strips.

Particular attention was drawn to the report of the PhD, assistant professor of Roman Gorbachev, which arrived from Manchester to Novosibirsk from A.Geym laboratory The report was devoted to the synthesis of two-dimensional laminates of noncarbon nature such as boron nitride, niobium and molybdenum diselenide, and others, and to the study their superconductivity.

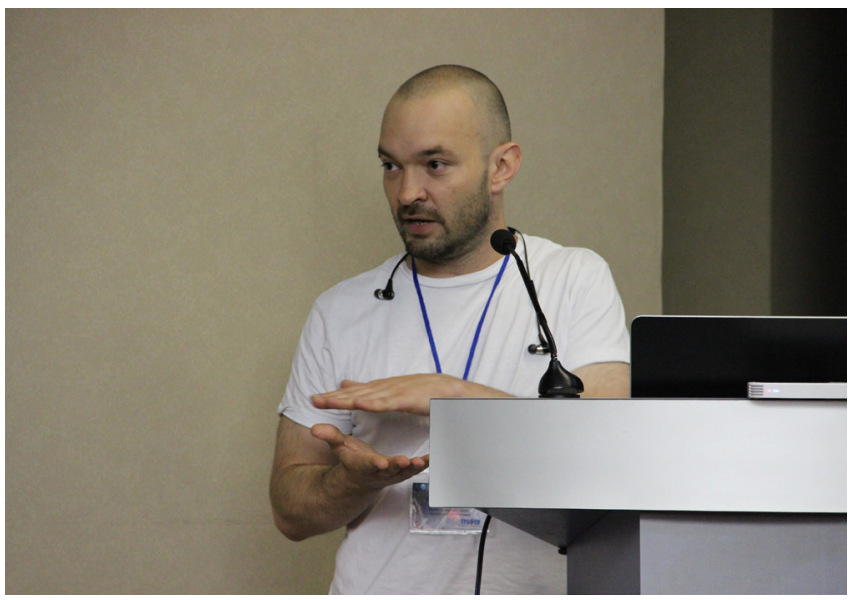

Roman Gorbachev, University of Manchester, England 
The plenary session of the first day report completed of Nikolai Uvarov from a group of authors from the Institute of Solid State Chemistry SB RAS and the Novosibirsk State University about the synthesis of the polygraphene and its processing in order to increase its specific capacity as a supercapacitor electrode material.

A feature of the conference, which revealed on the first day and remained to its end, was an unusually activity, lively reaction of the audience, the discussion that accompanied each report before the ten questions, transforming the conference into a hot discussion club of eager to communicate participants, unlike typical for conferences conveyor run of the declared program, that voicing its participants one after another, leaving tribune.

Breakout session of the first day of the conference - Synthesis of graphene and related structures - leaded Victor Yakovlevich Prinz, Dr Sci. Phys\&Math, professor, head Laboratory of Physics and technology of three-dimensional nanostructures of the Institute of Semiconductor Physics SB RAS, who noted the importance of subjects synthesis: "semiconductor technology have long been ready to take graphene, has long been achieved high performance of graphene devices, it's left for a little - the producing high-quality graphene in the required volumes."

The first report here is of Dr Sci. Phys\&Math, prof. Peter Belobrov from Krasnoyarsk Institute of Physics Kirensky, that advocated the diamond electronics as a pure carbonic electronics, has left more questions than answers

In report PhD Phys\&Math Pauline Kughir from the

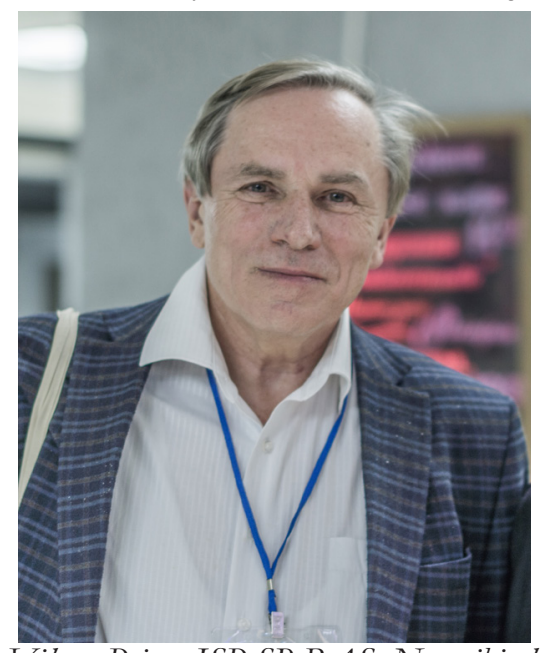

Viktor Prinz, ISP SB RAS, Novosibirsk

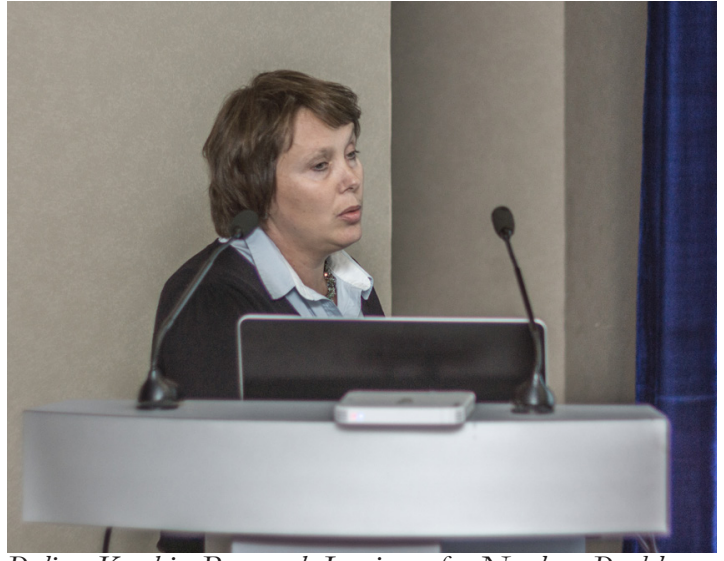

Polina Ku乏hir, Research Institute for Nuclear Problems of

Belarusian State University, Minsk

Minsk Institute of Nuclear Problems of the Belarusian State University, together with the Finnish and Belgian colleagues, presented synthesis of graphene-polymer (PMMA) sandwiches and study their screening properties giga- and terahertz radiation.

Report PhD Phys\&Math Svetlana Smagulova from Yakut Northeastern University (Laboratory of graphene nanotechnology) about the synthesis of oxide-graphene films, the study of their properties and the use of a wide range of applications - for laser lithography, humidity sensors, strain sensors, biosensors and protective antibacterial coating

Report PhD Chem Anatoly Lobach with coauthors from Chernogolovka and Keldysh Center - about the synthesis of three-dimensional hybrids of two-dimensional graphene and one-dimensional carbon nanotubes by dispersing SWCNT in aqueous suspension of graphene oxide. Hybrid film obtained by vacuum microfiltration suspensions, studied their Raman spectra and electrical conductivity in comparison with the original components.

Report PhD Chem Alexander Melezhik with colleagues from Tambov TSU - about industrial

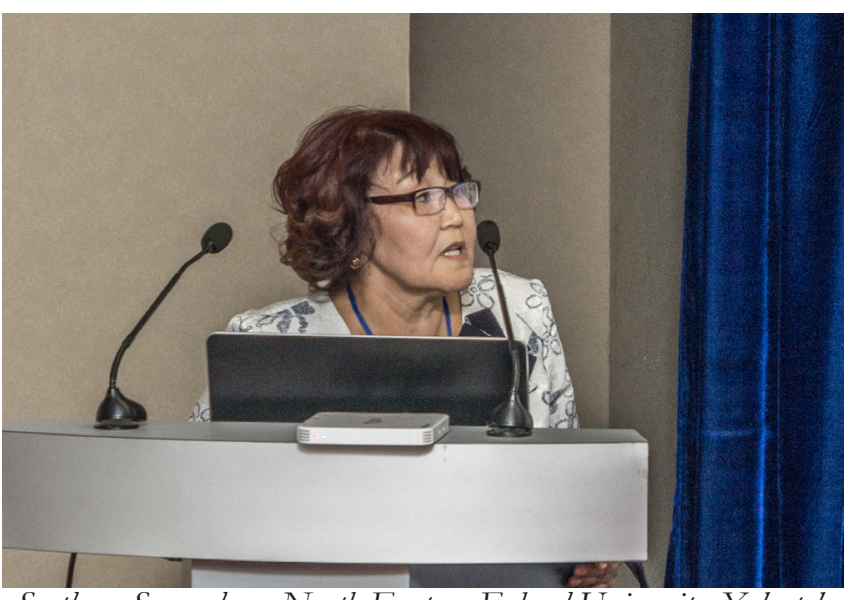

Svetlana Smagulova, North-Eastern Federal University, Yakutsk. 


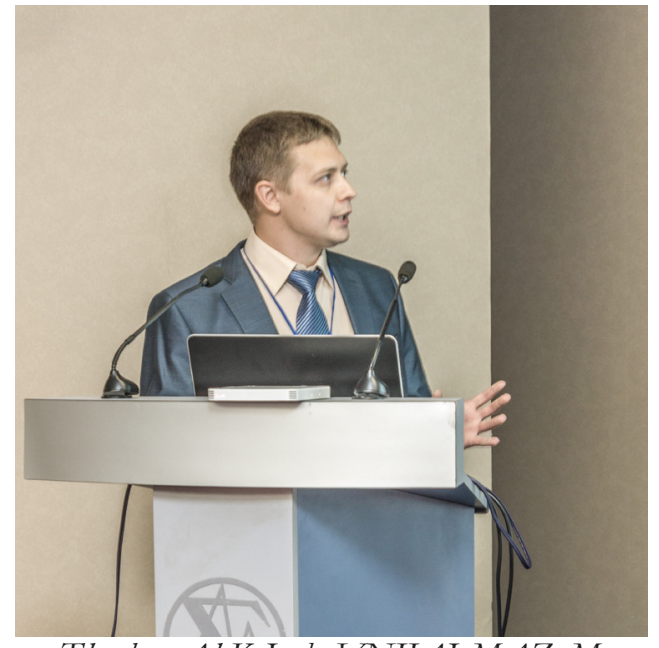

Sergey Tkachev, AkKoLab, VNILALMAZ, Moscow

technology of synthesis of graphene nanoplates of 2-5 graphene layers stabilized by surfactants, and of 15 layers without stabilizers, including modified nanoplates, caused a number of criticisms.

Report PhD Chem Sergei Tkachev with colleagues from the moscow LLC AkKoLab (VNIIALMAZ) - about the synthesis gram quantities of graphene through the graphene oxide restoration by supercritical isopropanol. There is a problem obtaining a graphene material, that is not lost the famous unique properties of graphene - electrical and thermal conductivity, strength, transparency and others, that inherent in only one of his flakes. Graphene oxide was synthesized by Hammers natural graphite is oxidized to the oxide, which is under the powerful ultrasound $(\sim 20 \mathrm{kHz}$, up to 1 $\left.\mathrm{W} / \mathrm{cm}^{3}\right)$ is stratified up to the graphene oxide. The last is restored by supercritical isopropanol in an autoclave.

In the report of PhD Phys\&Math Maxim Rybin from moscow GPI and his colleagues

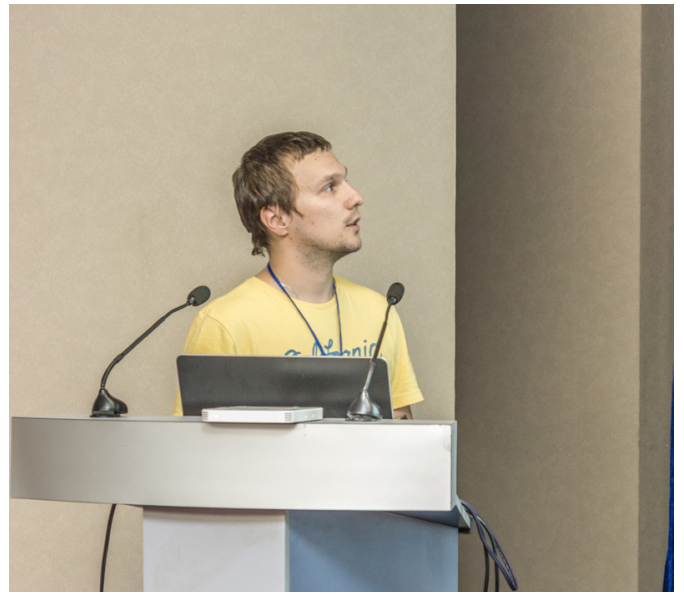

Maksim Rybin, GPI RAS, Moscow

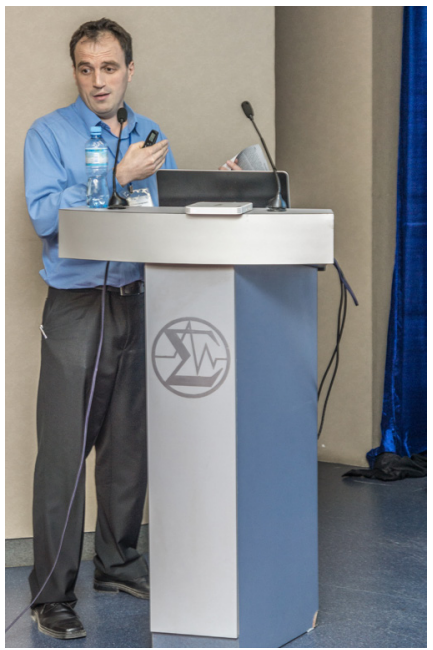

Andrey Pakhnevich, ISP SB RAS, Novosibirsk

from Dukhov Institute of Automation and MIPT presents the results of graphene synthesis on copper foil through a chemical vapor deposition (CVD-process) - most relevance and perspective on today - with a subsequent doping (introduction of impurities in graphite) by plasma in environment of different gases and shift control of its properties by various spectroscopic and microscopic methods.

In the work of $\mathrm{PhD}$ Phys\&Math Andrew Pakhnevich and his colleagues from the laboratory VJ Prince (ISP SB RAS) CVD-synthesis of graphene was performed on the liquid copper (copper foil at $1083^{\circ} \mathrm{C}$ and above) in a quartz reactor in an argonhydrogen atmosphere with the addition of methane. By atomic force and scanning electron microscopy provided data to build the model of growth of graphene films.

In the work $\mathrm{PhD}$ Chem Dmitry Pinakov and his

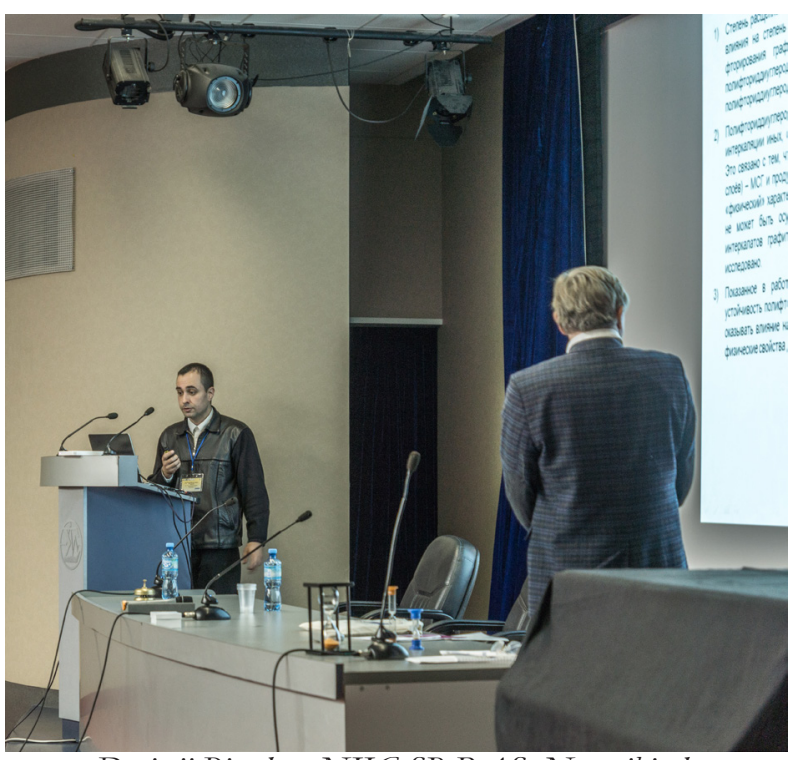

Dmitrii Pinakov, NIIC SB RAS, Novosibirsk 


\section{NANOSYSTEMS}

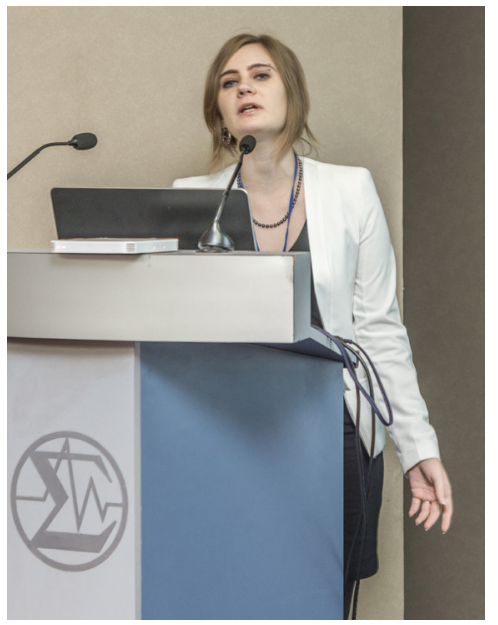

Ekaterina Fedorouskaya, NIIC SB RAS, Novosibirsk

colleagues from the laboratory V.E. Fedorov (NIIC SB RAS) the multilayer graphene is synthesized by thermal decomposition poliftoriddicarbon $\mathrm{C}_{2} \mathrm{~F} \cdot \mathrm{xR}$, is fluoridated his by threechloride fluorine (for adjusting the band gap of graphene); is revealed the influence of size effects (splitting multilayer graphene) on the properties of such ftoriddi.

In the work PhD Chem Catherine Fedorovskaya with co-authors from lab. A.V. Okotrub (NIIC SB RAS) are synthesized graphene materials for supercapacitors from graphite intercalates and then use them as a framework for the deposition of polyaniline at its chemical polycondensation with produce composites with a specific capacity up to hundreds of F/g. Data of IR, XPS- and NEXAFS-spectroscopy obtained composites allowed to estimate their electrochemical properties.

The first day of the conference concluded by buffet at the restaurant the first floor of House Scientists.

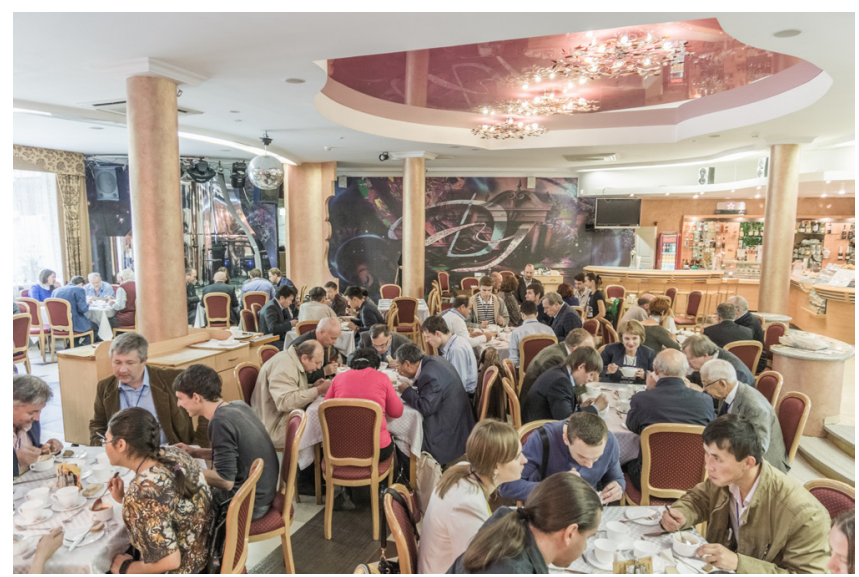

FIRST RUSSIAN CONFERENCE "GRAPHENE - 113 MOLECULE AND 2D-CRYSTAL" (Novosibirsk, 8-12.09.2015)

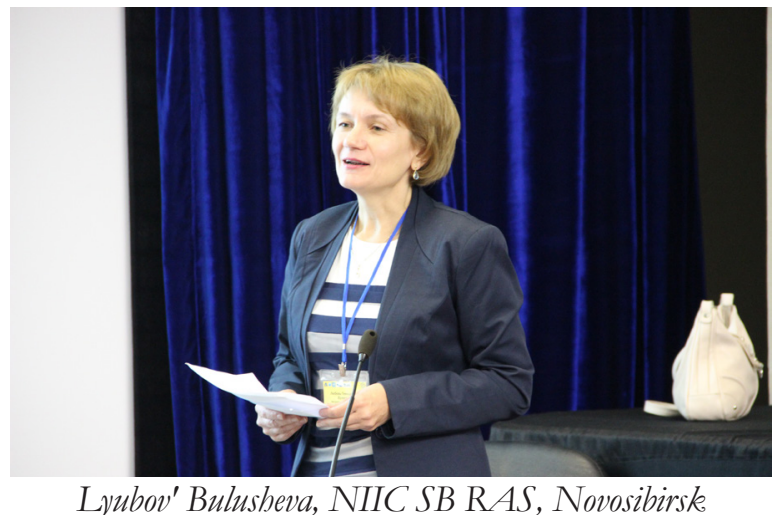

3. THE SECOND DAY. THEORETICAL METHODS AND THE DIAGNOSTICS OF GRAPHENES

The plenary session of the second day under the chairmanship of Dr Sci. Chem Lyubov Gennadievna Bulusheva (lab. A.V. Okotrub NIIC SB RAS) opened Dr Sci. Phys\&Math, prof. Leonid Chernozatonskii from the Moscow Institute of Biochemical Physics NM Emanuel RAS. He presented a review of properties and applications of two-dimensional graphene layers, bilayers, nanostructures of dichalcogenides of transition metals, structures with atoms, embedded between layers and/or in layers, as well as devices based on them in nanoelectronics, electromechanics, optics and photonics. "Graphene has exhausted itself," as assures A.Geym is now, but he removed "Landau ban" on two-dimension of crystals, thus turning perception of the world by the eyes in the dimension of the processes and phenomena, i.e. graphene has become, except other things, specific object for study space as such.

The next report - the work of a renowned expert in memcomputing - computing paradigm

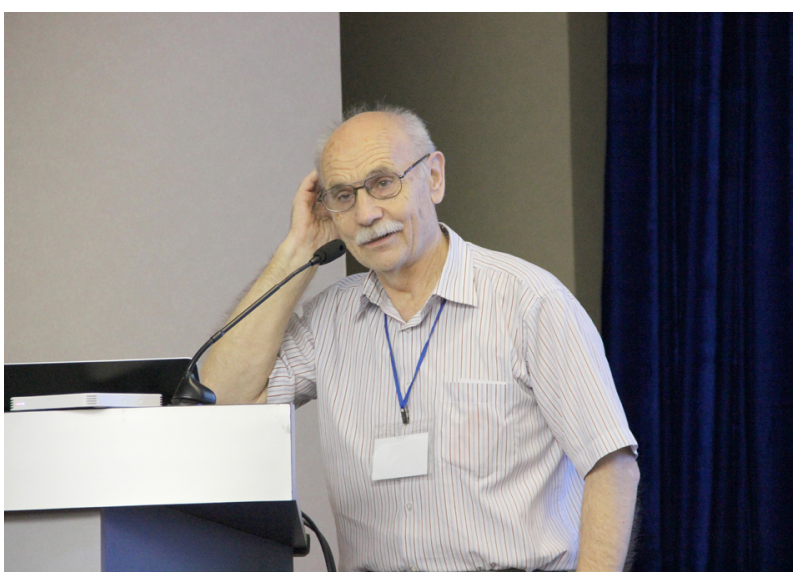

Leonid Chernozatonskii, IBCP RAS, Mosconn 


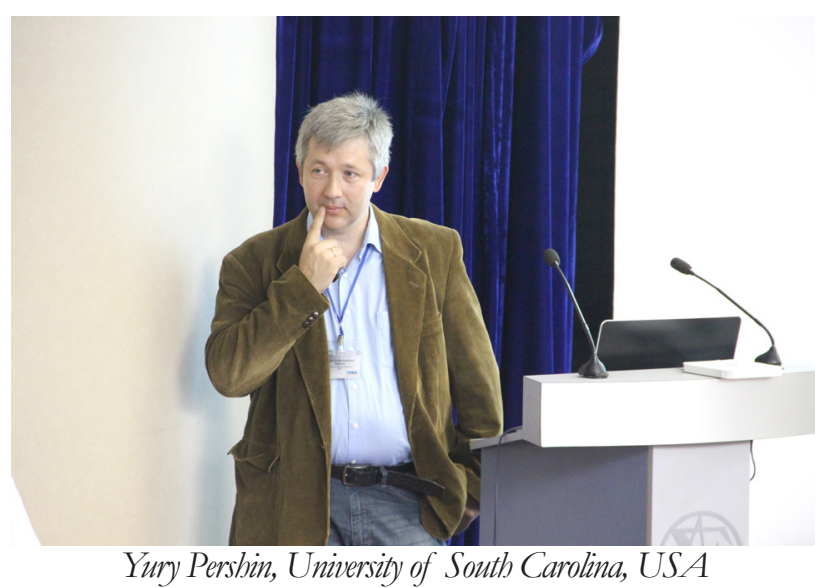

for the storage and processing of information on a single physical platform, of its founder, Dr Sci. Phys\&Math, prof. Yury Pershin from the University of South Carolina (Columbia, USA) with co-autors, in which is represented the realization of the computer's memory by using the graphene membrane of the capacitive system of memory.

In the work of PhD Phys\&Math Pavel Sorokin from the Technological Institute for Superhard and Novel Carbon Materials (TISNCM, Troitsk, Moscow) with co-authors from the University of Houston and Michigan, is studied "chemically induced phase transition" in the formation of ultrathin diamond film with a thickness up to $15 \mathrm{~nm}$ multilayer graphene, and determined the critical the thickness of graphitization such films ion composition.

Dr Sci. Phys\&Math, prof. Eugene Belenkov (Chelyabinsk State University) presented a classification of structural types of carbon compounds from graphene to carbyne and

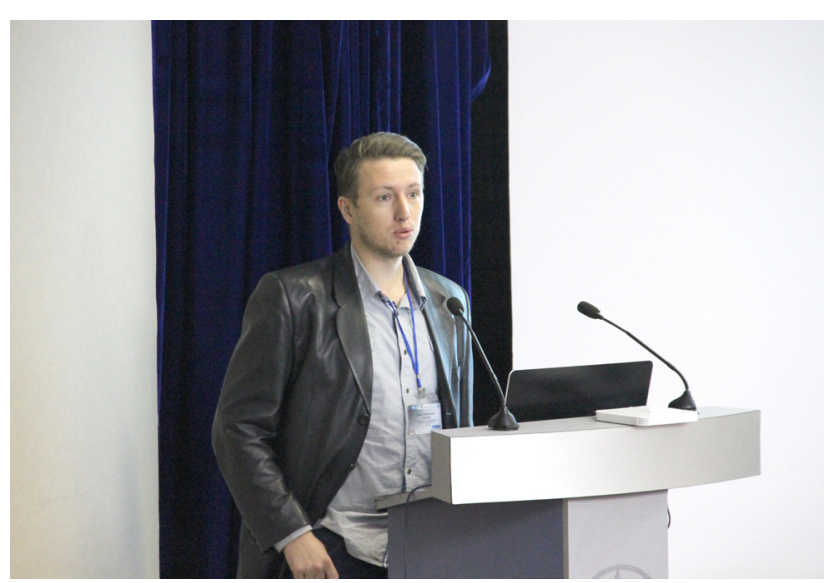

Pavel Sorokin, TISNCM, Moscow, Troitsk.

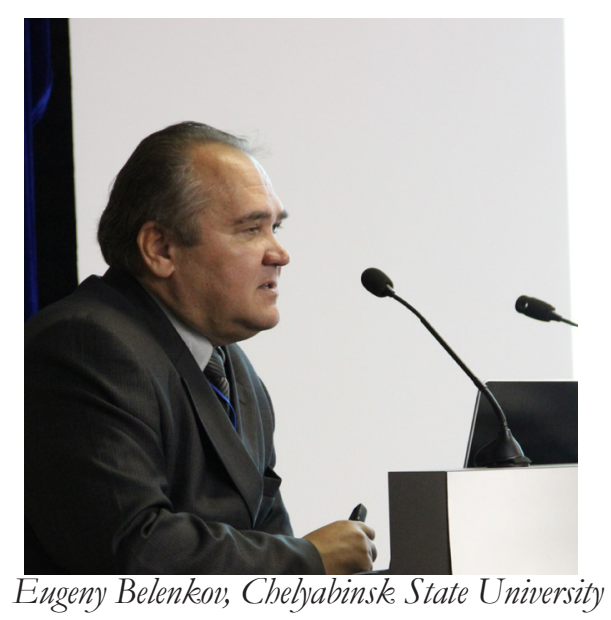

diamond, considering the type of chemical bonds in the compound, as well as the results of calculations by the density functional theory of the structure and electronic properties of a number of new graphene layers and $3 \mathrm{D}$ graphite phases.

Dr Sci. Phys\&Math, leading researcher laboratory of physics and technology of threedimensional nanostructures ISP SB RAS Irina Antonova et al presented a paper in which, using the developed in the laboratory of an original method of fluorination graphene created it conductive islands - quantum dots with diameters from 400 to $10 \mathrm{~nm}$ and a density of about $10^{9}$ per square $\mathrm{cm}$ and investigated the transport and the relaxation times of nonequilibrium charge in them with lighted (daylight, $\sim 10^{18}$ foton/ $\mathrm{cm}^{2} \mathrm{~s}$ ) and without it; are determined the values of activation barriers separating the quantum dots for the flow of current, and is studied their electronic structure.

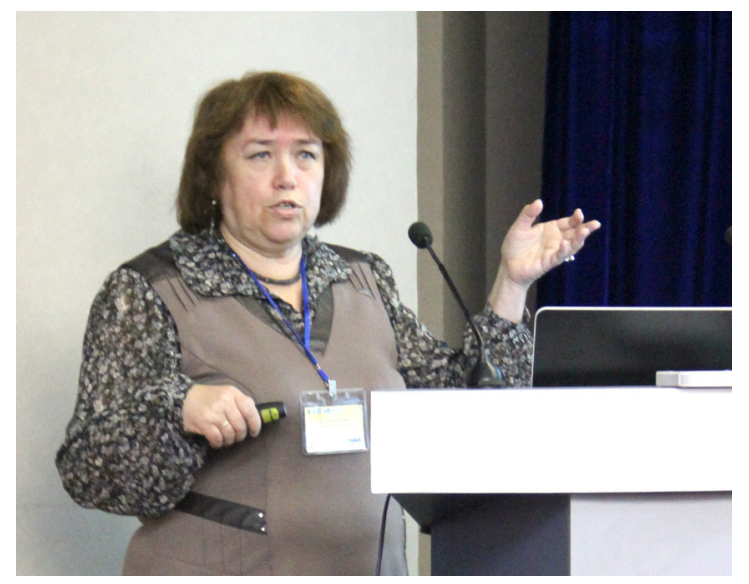

Irina Antonova, ISP SB RAS, Novosibirsk 


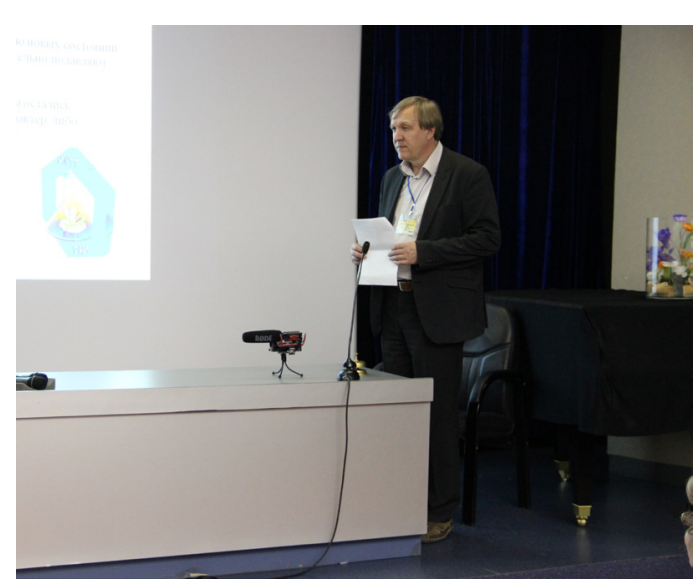

Alexander Okotrub, NIIC SB RAS, Novosibirsk

Breakout Session - Theoretical methods in application to graphene materials - under the chairmanship of Alexander Vladimirovich Okotrub began with report Galina Vasilyeva et al from St. Petersburg Ioffe Institute and Hanover Institute of Solid State Physics, which presented a study two-layer graphene on $\mathrm{SiO}_{2}$ in the magnetic field in a vacuum. Shows the dependences of the magnetoresistance on the width of the sample as a function of its geometry and of scattering mechanism of carriers, including negative magnetoresistance at displacement of the Fermi level from the point of electrical neutrality.

In the report $\mathrm{PhD}$ Phys\&Math Olga Sedelnikova (lab. A.V. Okotrub) about interlayer interactions in bilayer graphene at disorientation layers (turn through a small angle with respect to one another) presents the results of theoretical and experimental studies of new features Van Hove in electronic density of states of graphene, its electronic, optical and plasmonic properties.

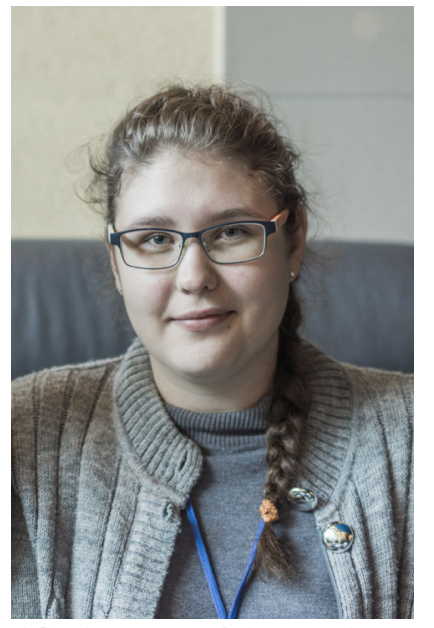

Ol'ga Sedel'nikova, NIIC SB RAS, Novosibirsk

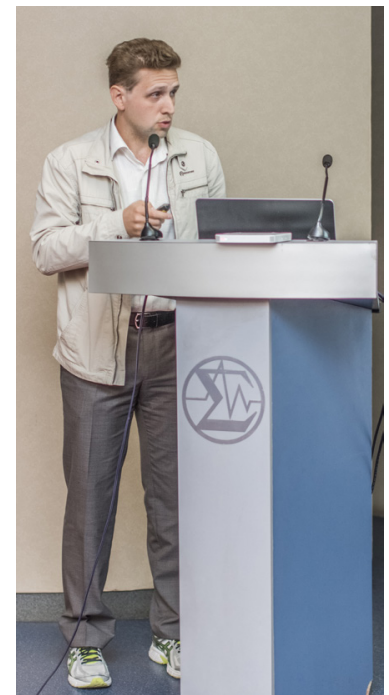

DmitryUsachev, Physical Faculty St.Petersburg State University

In the work of PhD Phys\&Math Dmitry Usachev from St. Petersburg State University is held a CVD-synthesis of good-oriented monolayers of $\mathrm{N}$-graphene (nitrogen-doped) and B-graphene (boron-doped) on the surface of a large area of the triazine and carborane molecules, respectively. Photoelectron spectroscopy with angular resolution identifies the possibility to manage the electronic structure of graphene by using doping and interaction with the substrate.

In the work Dr Sci. Phys\&Math Ernst Kurmaev from Ekaterinburg Institute of Metal Physics them. MN Mikheyev X-ray and Raman measurements showed no corrosion of copper coated with a monolayer of graphene, that lay in the air up to 1.5 years. The calculations from first principles of density functional theory (DFT) have shown that copper is oxidized only in the presence of a carbon vacancies in graphene.

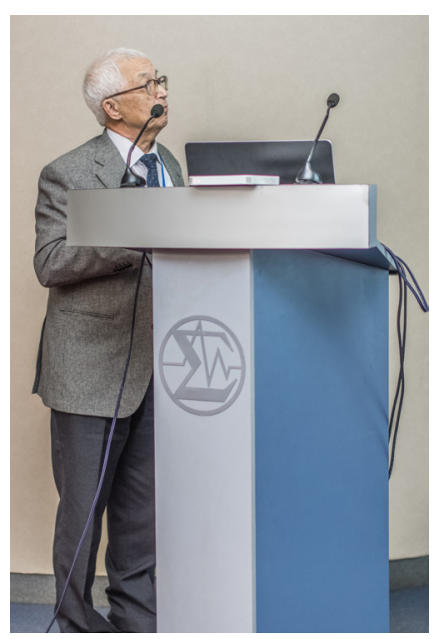

Ernst Kurmaev, IMP UB RAS, Ekaterinburg 


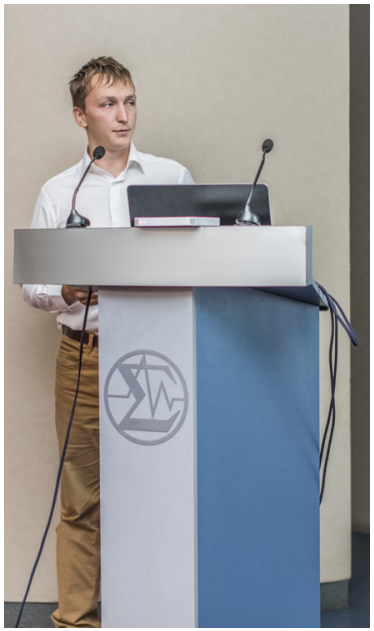

Vladimir Voroshnin, Physical Faculty St.Petersburg State University

Vladimir Voroshnin and his colleagues from St. Petersburg State University grew the graphene by using cracking on a single crystal of nonmagnetic rhenium with splitting at the spin of surface electron states and the intercalation of gold under graphene. Herewith in graphene inducing the spin-orbit splitting of the $\pi$-states near the Fermi level while maintaining linearity of the dispersion relation, which was confirmed by measurements of the electron and spin structure using photoelectron spectroscopy with angular resolution.

$\mathrm{PhD}$ Chem Victor Koroteev of NIIC SB RAS (lab. Okotrub AV) and colleagues from the BIC SB RAS and the Spanish center CIC nanoGUNE Consilider investigated $\mathrm{MoS}_{2}$ formation on the surface of various carbon materials, electronic structure and catalytic activity of the samples according to the different synthesis conditions.

$\mathrm{PhDChem}$ AlexanderMikheyevand $\mathrm{PhDChem}$ Victor Makotchenko of NIIC SB RAS showed
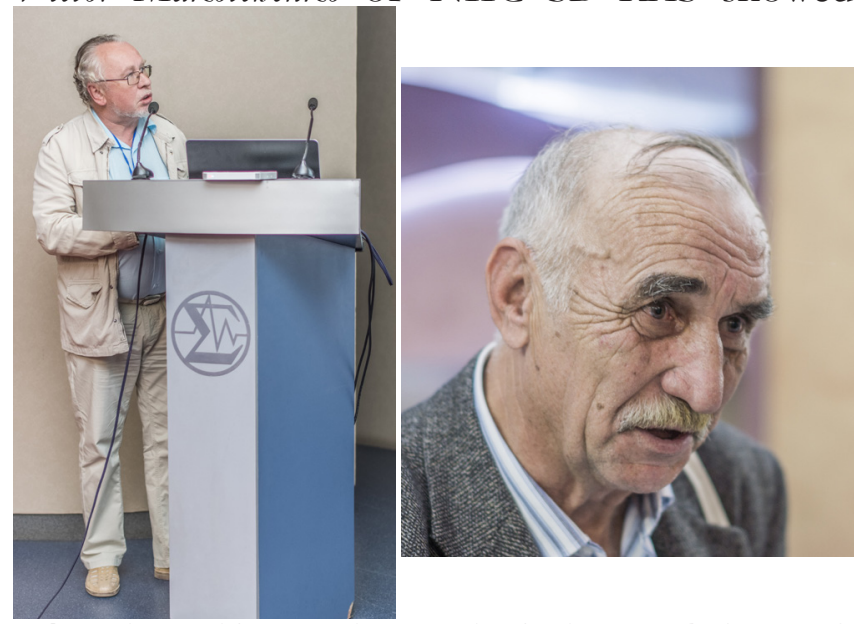

Alexander Mikheev, Viktor Makotchenko, NIIC SB RAS, Novosibirsk

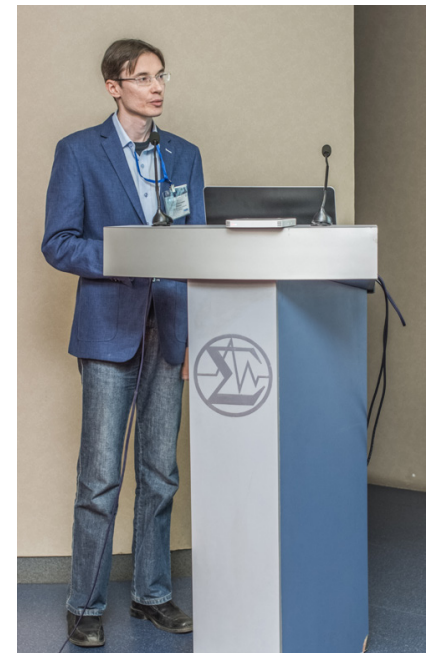

Andrey Enyashin, ISSC UB RAS, Ekaterinburg

that during microwave heating of fluorinated intercalated graphite occurs the formation of multilayer graphene at temperatures several times more lower than by conventional heating.

$\mathrm{PhD}$ Chem Andrew Enyashin from Ekaterinburg ISSC of RAS(UB) presented the work on modeling the stability of grain boundaries as a linear defects in monolayers dichalcogenides. Studied their impact on the electronic and transport properties of semiconducting $\mathrm{MoS}_{2}$.

PhD Phys\&Math Alexander Ponomarev from the Tomsk Institute of strength physics and materials science with co-authors from Tomsk University presented the quantum-mechanical calculation of the density of electronic states near the Fermi level of graphene and the impact of structural defects of graphene on its electronic transport

PhD Phys\&Math Georgy Fedorov from the



Alexander Ponomarev, ISPMS SB RAS, Tomsk. 


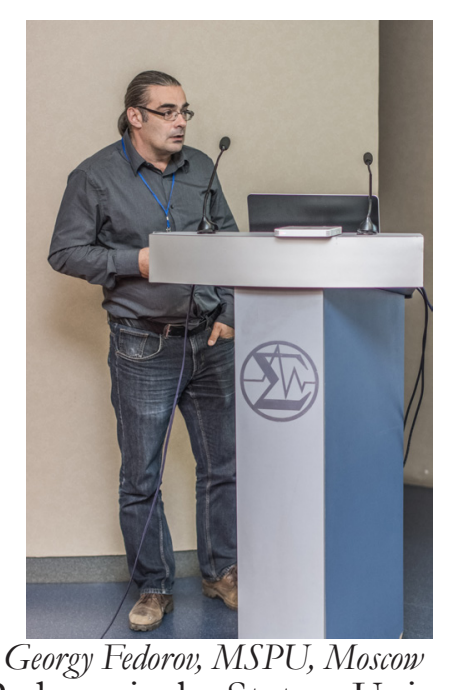

Moscow Pedagogical State University and colleagues from the MIPT, the Kurchatov Institute and the GPI RAS presented the work on graphene as a base sensor element for detectors of terahertz radiation at room temperature. Optimization of their configuration requires the determination of the contribution of various physical mechanisms in response of graphene at the radiation. Shows the results of irradiation $(200 \mu \mathrm{W}, 140 \mathrm{GHz})$ asymmetric structures based on CVD-graphene. Depending on the type of matching of radiation with the drain, source and gate of detector received fotothermoelectrical or plasmon response (up to $10 \mathrm{~V} / \mathrm{W}$ ) of graphene

Dr Sci. Tech, prof. Kurbangali Tynyshtykbaev from the Kazakh Nazarbayev University in Astana and his colleagues from Chernogolovka Institute of Microelectronics Technology and High Purity Materials RAS presented the results of measurements of microamperes acoustical

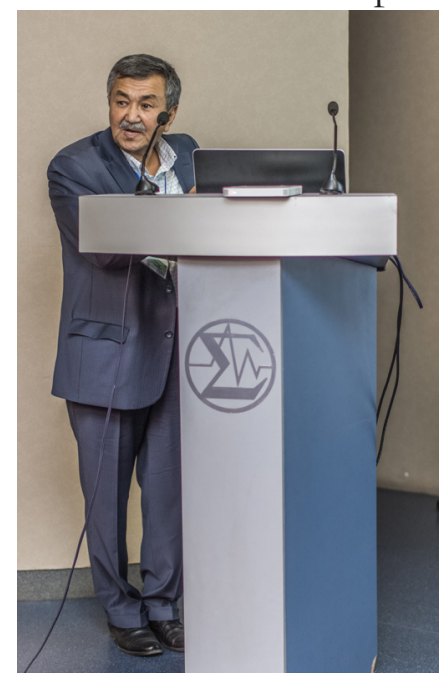

Kurbangali Tynyshtykbaev, NazarbayevUniversity, Astana

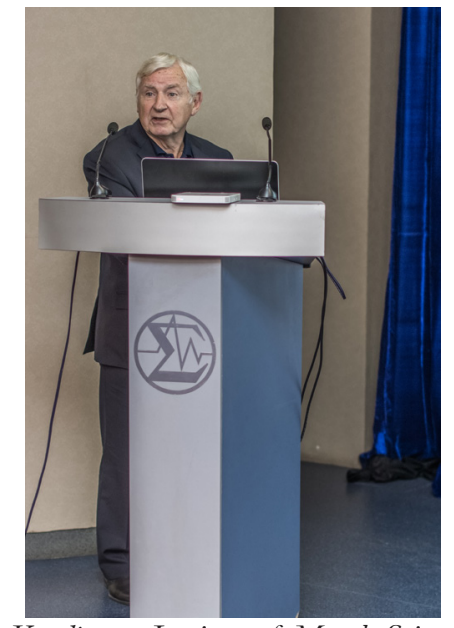

Yury Nechaev, Kurdjumov Institute of Metals Science and Physics of Bardin Central Research Institute of Ferrous Metallurgy, Moscow

currents in the CVD-synthesized 2-3-ply graphene on piezo substrate (polycrystalline $\mathrm{Ni}$-film) under the influence of a $\mathrm{mW}$ surface acoustic wave on $\sim 100 \mathrm{MHz}$ resonance frequency. Imposing a small bias voltage along with change in the amplitude of the surface wave determined the sign and magnitude of the induced acoustoelectric current.

Dr Sci. Phys\&Math, prof. Yuri Nechayev in collaboration with V. Filippova (Institute of Physical Metallurgy them. Kurdyumov of Bardin Central Research Institute CHERMET) presented the results of the thermodynamic analysis of the characteristics of the thermal stability of hydrogenated graphene, as well as the mechanism of the process of hydrogenation and dehydrogenation (according to the literature).

\subsection{POSTER SESSION}

After the reports of the second day was declared a poster session. Poster presentations - about sixty filled a spacious corridor of mezzanine of winter garden (continuation of hall at second floor) all the days of the conference and were available for discussion at all coffee breaks and breaks between sessions. Among poster presentations there were many such that it would be preferable to hear in the audience of the conference, however, due to its restriction in time, such works had to be content with a poster presentation.

Some examples of posters and episodes of poster session are shown in the attached compilation. 

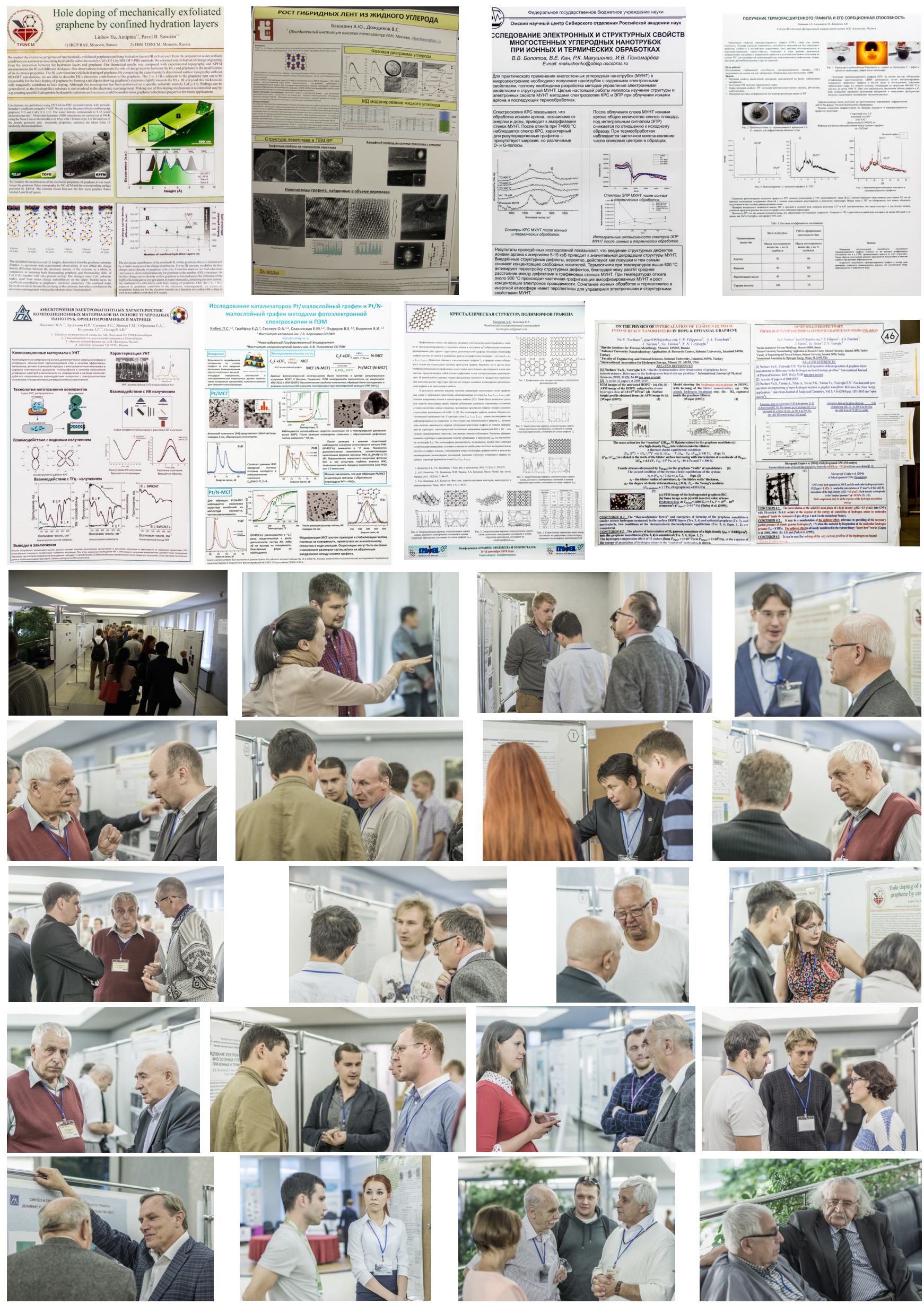


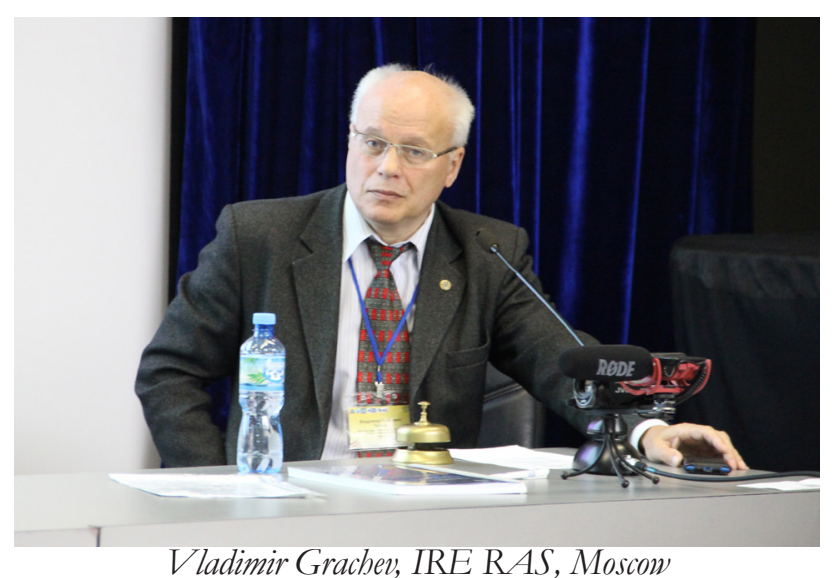

4. DAY THREE. MATERIALS AND DEVICES BASED ON GRAPHENE

The third day of the conference began with a plenary session chaired by Vladimir Ivanovich Gracher (Institute of Radio Engineering and Electronics, Russian Academy of Sciences), with a presentation of Dr Sci. Phys\&Math, prof. Alexander Eletski of the Kurchatov Institute (with co-authors from the Moscow Institutes of MEI and Emmanuel RAS), which, after consideration of the problems of using CNT array as a cold electron field emitter presented calculations of model vertically oriented rectangular sheet of graphene, which emits electrons from the edge of the sheet. Received the value of the work function of the electrons for the graphene fragments, functionalized by hydrogen. Shows the existence of two modes of emission (of the order of tens of amperes per $\mathrm{cm}^{2}$ ): from the top of sheet when the applied voltage is low, and from the its center in the high field, which reveals in the fracture of current-voltage characteristics of graphene in coordinates of Fowler-Nordheim,

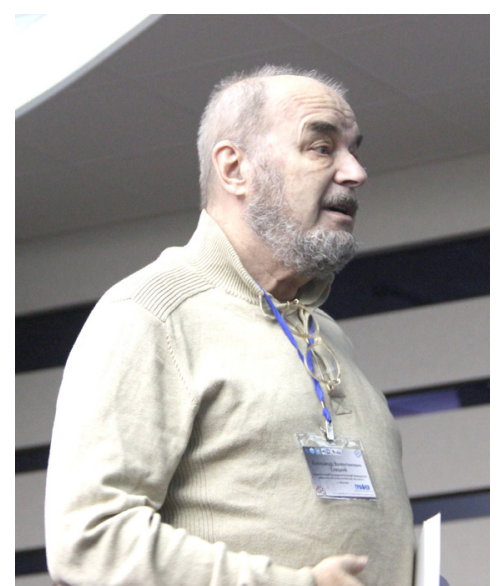

Alexander Eletskii, Kurchatov Institute, Moscow

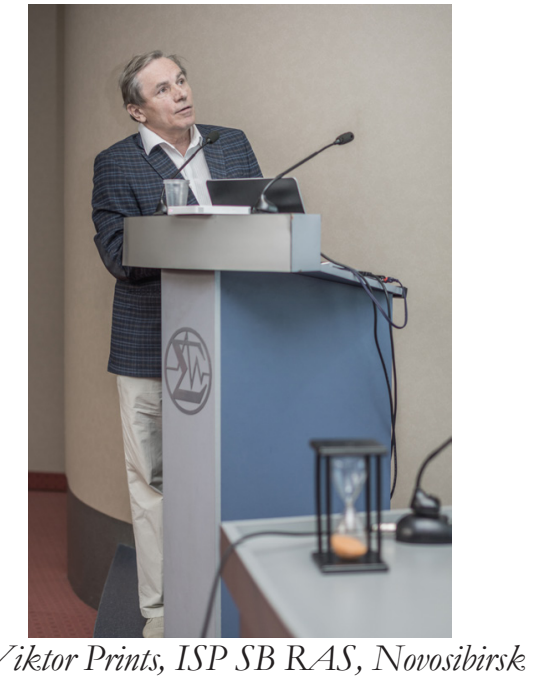

that confirmed in an experiment. Offered the structure of the emitter with a uniform emission from all regions, that, in principle, may be implemented by existing equipment of processing fragments of graphene.

Dr Sci. Phys\&Math, prof. Victor Prince (ISP SB RAS) began his a very rich overview of graphene devices and structures with doubt of the replacement in the coming decades silicon electronics by the graphene: "today trillions of the working transistors on a single silicon chip can not be replaced on the trillions modern CNT, as unattainable as long as for graphene and the quality of silicon, which has at $10^{12}$ atoms the only one defect. This was followed by presentation of graphene devices with their physics, from ultra-fast and wide-band photodetectors, sensors, transistors, field emitters and graphite + heterostructures, quantum dots etc. to the graphene nanophotonics, nanoplasmonics with atomic optoelectronic and plasmonic devices and flexible electronics on heterostructures; with the certainty that after a some recession enthusiasm, graphene will come to a plateau of productivity, taking up its significant niche in the electronics.

Dr Sci. Phys\&Math, prof. Alexander Obraztsov et al (Faculty of Physics, Lomonosov MSU) presented an overview of many years of research multi-emitter auto cathode: CVD-synthesized on a silicon substrate plate of graphite with a thickness from several to tens of nanometers, consisting of a few atomic layers with 


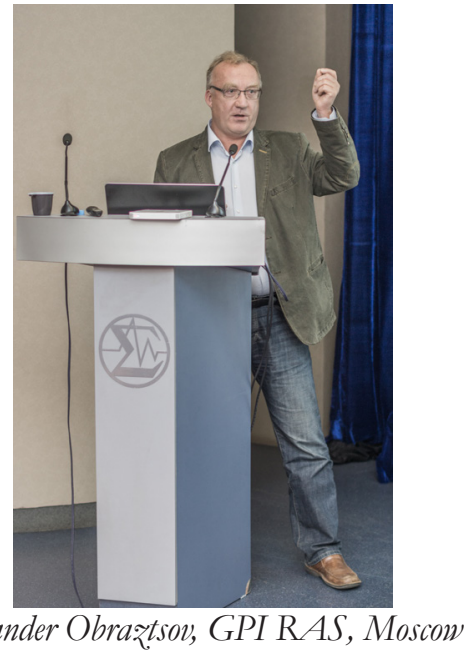

Alexander Obrątson, GPI RAS, Moscow

perpendicular to the substrate orientation and with a high aspect ratio. Emission occurs from the blade edge of such auto cathode. Herewith the blade edge is curved. Its bending has a diamond heterostructure. It is shown that the classical description of the field emission in this case requires a supplement - the introduction of gain as the ratio of the local and average fields; At high voltages the energy spectra reveal the emission from the inner levels, herewith the double potential barrier with an additional level has resonance nature.

Sectional session - materials and devices based on graphene and related structures - began with the report of $\mathrm{PhD}$ Chem Boris Tarasov et al from Chernogolovka (IPCP RAS) about synthesis the composites for hydrogen energy based on graphene-like materials (GLM), obtained while thermal reducing of graphite oxide. Were obtained Pt/GLM, NiO/GLM (from mixtures

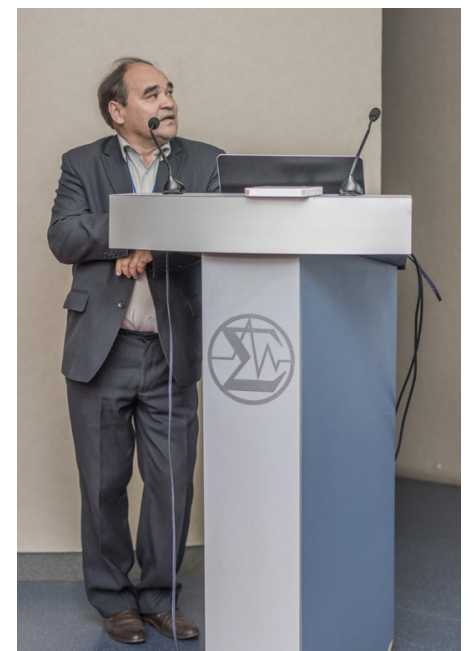

Boris Tarasov, IPCP RAS, Chernogolovka

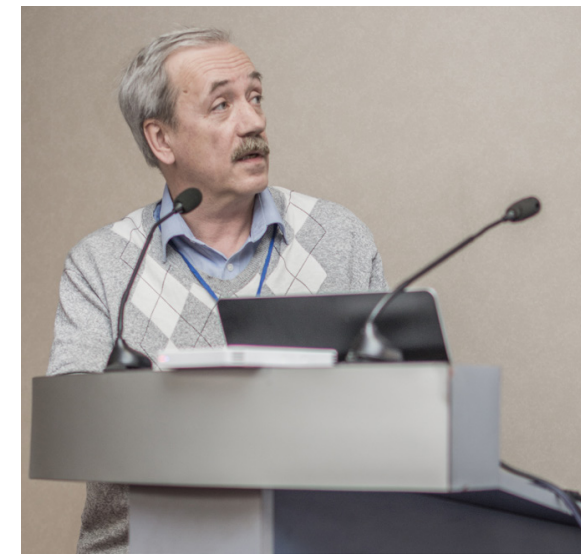

Alexander Lebedev, Ioffe Institute, St Petersburg

$\mathrm{OG}$ and salts of $\mathrm{Ni}$ ), Ni/GLM. Also were prepared composites CNS/GLM (CNS - carbon nanostructures - nanofibers and nanotubes). Studied the influence of the synthesis conditions on the properties of CNS and composites, as well as catalytic properties of composites

In the work by Dr Sci. Phys\&Math, prof. Alexander Lebedev from the Joffe PhysicoTechnical Institute et al from Holding "Nitride crystals" (St.Petersburg) and the Finnish Aalto University graphene films are formed while thermal destruction of the surface of silicon carbide. Films studied by methods Raman, Auger spectroscopy and RHEED, measured current-voltage characteristic, the Hall effect at temperatures of $2-300 \mathrm{~K}$ and so on. Is made stable as $\mathrm{NO}_{2}$ gas sensor with a record sensitivity.

PhD Chem Valery Melnikov, in collaboration with MV Gudkov from the Institute of Chemical Physics RAS presented a report on the original method of obtaining graphene material with

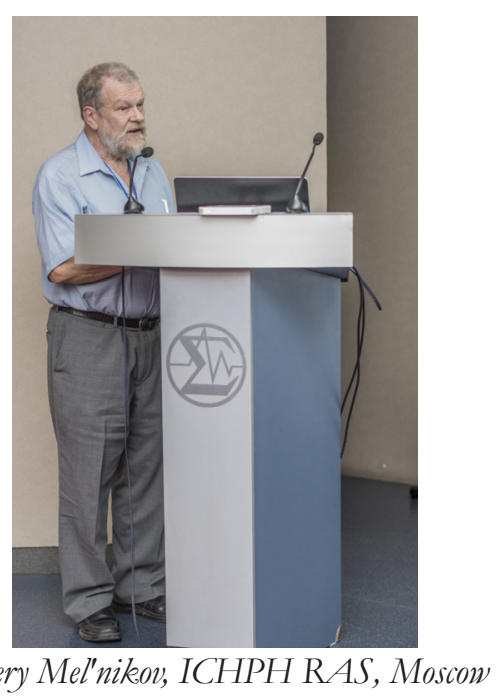




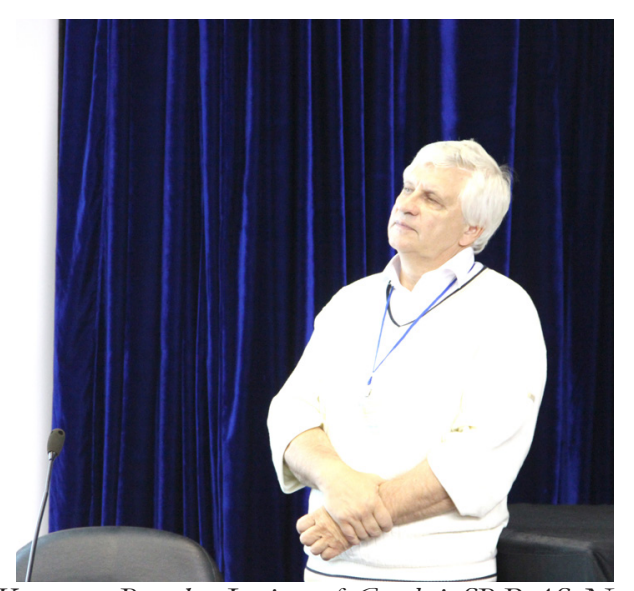

Vladimir Kuznetson, Boreskov Institute of Catalysis SB RAS, Novosibirsk high specific surface by explosive reduction of graphite oxide through vapors of hydrazine at room temperature.

After lunch, chaired by PhD Chem Vladimir Leonidovich Kuznetsov from the Institute of Catalysis SB RAS sectional session report continued Dr Sci. Tech Sergei Grigoriev from the MEI and coworkers of the Kurchatov Institute and the Dolgoprudny firm "Deltarus", which presents the results of the synthesis and study of reduced graphene oxide with a specific surface area of $600 \mathrm{~m}^{2} / \mathrm{g}$ with the deposited nanoparticles of platinum metals magnetron sputtering in a pulsed mode. Installed the optimum RGO content by adding it into composition of the electrocatalytic compositions of membrane-electrode cells of fuel with solid polymer electrolyte.

Nadezhda Nebogatikeva and colleagues from the ISP SB RAS presented the work on the original method of fluorination graphene suspension an aqueous solution of hydrofluoric

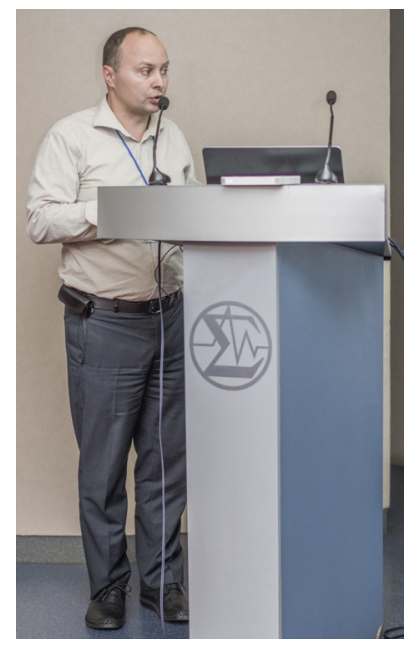

Sergey Grigiriev, MEI, Moscow

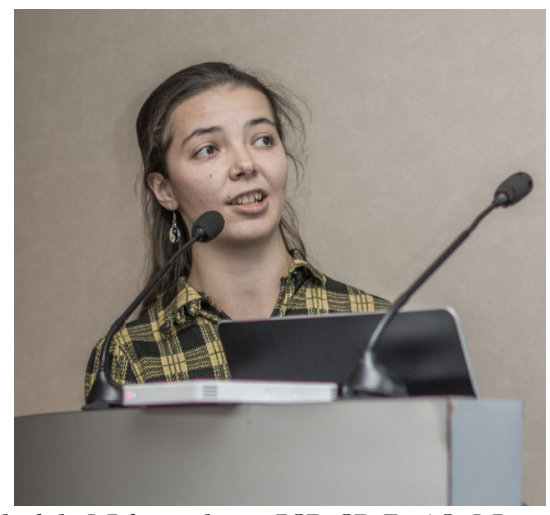

Nadez̧bda Nebogatikova, ISP SB RAS, Novosibirsk

acid to create a thin $(50 \mathrm{~nm})$ fluorografene films with high breakdown voltage of $\sim 10^{6} \mathrm{~V} / \mathrm{cm}$ and a low density of surface states $10^{10}$ per $\mathrm{cm}^{2}$ that is promising for practical applications.

In the report PhD Phys\&Math Victor Klesch and colleagues from the Physics Faculty of Lomonosov MSU and MIREA about graphene as the auto cathode the single-layer CVD-graphene large $(\sim 1$ $\left.\times 1 \mathrm{~cm}^{2}\right)$ square on the copper foil after the transfer on a quartz substrate, upon application of a small voltage due to the high aspect ratio consistently gave with its edge emission current with linear density of $0.1 \mathrm{~mA} / \mathrm{cm}$, which was visualized using fluorescent screen. By increasing the imposed voltage up to $\sim 360 \mathrm{~V}$ current, reaching $0.5 \mathrm{~mA} /$ $\mathrm{cm}$ sharply grows on several (>4) orders, gradually increasing after the jump, and gradually decreasing with decreasing voltage to its original value. Ie CVC current had hysteretic view that, apparently, due to the avulsion of the graphene edge from substrate by ponderomotive forces of field emission. These results show the row of new application of graphene emitters.

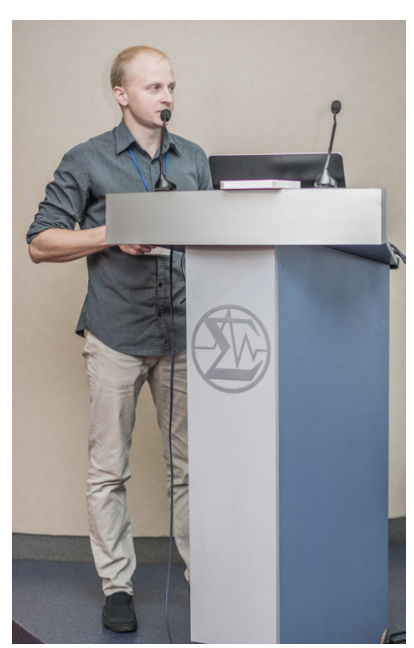

Victor Klesch, Faculty of Physics, Lomonosov MSU, Moscow 


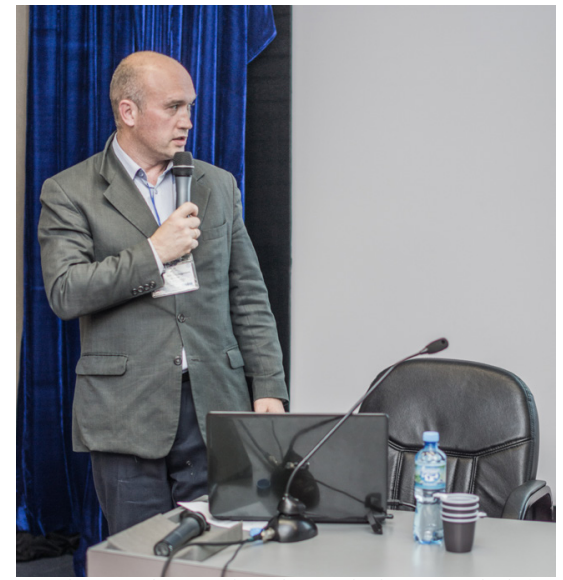

Alexander Reshetnyak, ISPMS SB RAS, Tomsk.

PhD Phys\&Math Alexander Reshetnyak from Tomsk Institute of Strength Physics and Materials Science and co-workers of the Kiev Bogolyubov Institute and University, presented model calculations of the optical and magnetooptical conductivity bilayer graphene in external electric and magnetic fields, in the so-called 2- and 4-band quantum-field approximation. Calculations of the contribution to the conductivity are made taking into account the multiple elastic scattering of electrons by impurities and structural inhomogeneities of short-range order using the exact Green's function. Received expressions for the angles of the Faraday and Kerr when radiation passes through the graphene on various substrates, can be used in the graphene optoelectronics.

In the work $\mathrm{PhD}$ Chem Alexei Rychagov from the Institute of Physical Chemistry and Electrochemistry Frumkin with colleagues from the AkKoLab shown that the electrochemical

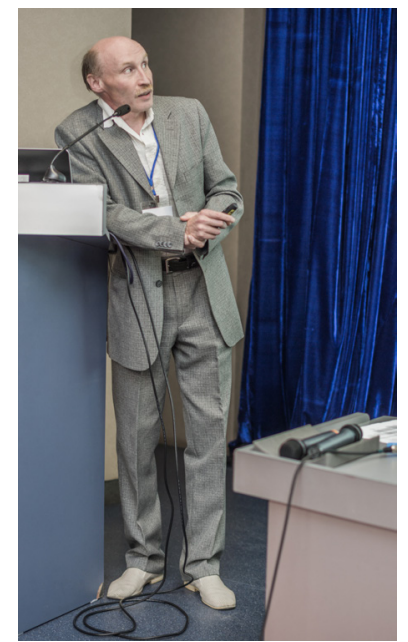

Alexey Rychagou, IPCE RAS, Moscow

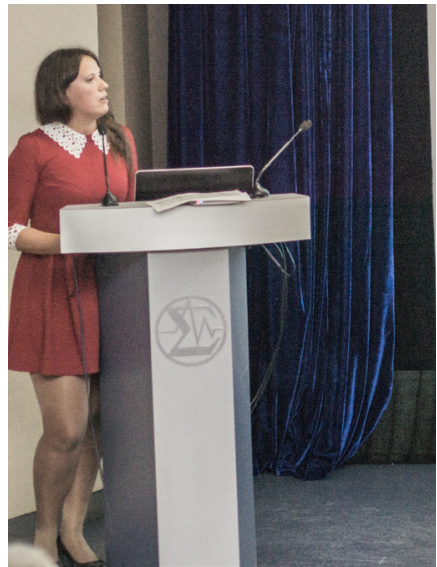

Anastasiya Nikolaeva, NIIgrafit, Moscow

reduction (ECR) of graphene oxide erases only loosely coupled oxides (epoxy and hydroxyl groups to the basal surfaces OG). It allows to form the electrodes directly in cell of supercapacitors. Redox polarization leads to the formation of electrodes having a large pseudocapacitance quinone-hydroquinone type. Proton conductivity of OG allows to form thin (3-5 $\mathrm{m})$ electrochemical groups of supercapacitors in the absence of an electrolyte. Prototype of symmetrical supercapacitor based on ECR OG is created and tested in the company AkKoLab.

$\mathrm{PhD}$ Tech Anastassia Nikolaeva from NIIgrafit with co-authors from MEI presented a message about the technology of little-layer graphene in aqueous solutions in the presence of surfactants and organic compounds by direct exfoliation of natural graphite under the influence of ultrasound.

$\mathrm{PhD}$ Tech Anton Dmitriev from the Chelyabinsk State University reported the results

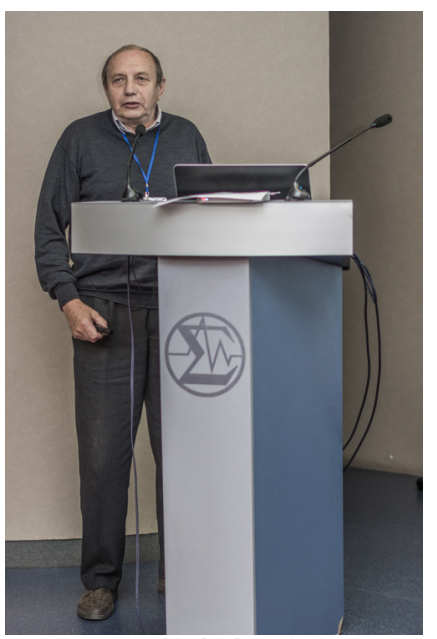

Anton Dmiytiev, Chelyabinsk State University 


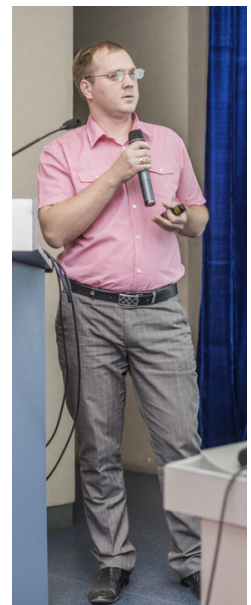

Alexander Samarov, ICCMS SB RAS, Kemerovo

of determining the thickness of the leaves of composite of expanded graphite and coal tar pitch on the proposed empirical formula.

In the report $\mathrm{PhD}$ Chem Alexander Samarov from IUHM of SB RAS, Kemerovo, presented the technique of synthesis of porous carbon materials $\left(>2000 \mathrm{~m}^{2} / \mathrm{g}\right.$ ) through the alkaline carbonization of various aromatic precursors, and the results of the study of one-dimensional and two-dimensional conduction micro- and mesoporous electrodes and specific capacity (up to $325 \mathrm{~F} / \mathrm{g}$ ) of dual-layer supercapacitors.

\subsection{PRESENTATIONS OF SPONSORS}

The third day of the conference concluded by presentation of representatives of sponsoring companies - participants of the conference with an exhibition of their products and stands on its activities: NT-MDT (Zelenograd), Graphene Materials (St. Petersburg), 10-nmbarVACOM (Jena, Germany), OCSiAl (Novosibirsk), CZL laboratory equipment (Moscow), DIA modern laboratory (Moscow), INUMiT (Lomonosov MSU), LLC AkKoLab (Moscow). Four representatives made detailed presentations that caused an active interest in the audience of the conference.

Some of samples of the exhibition presented below:
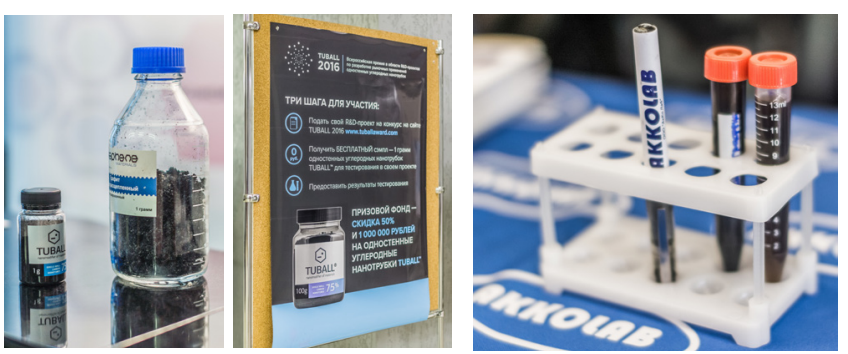

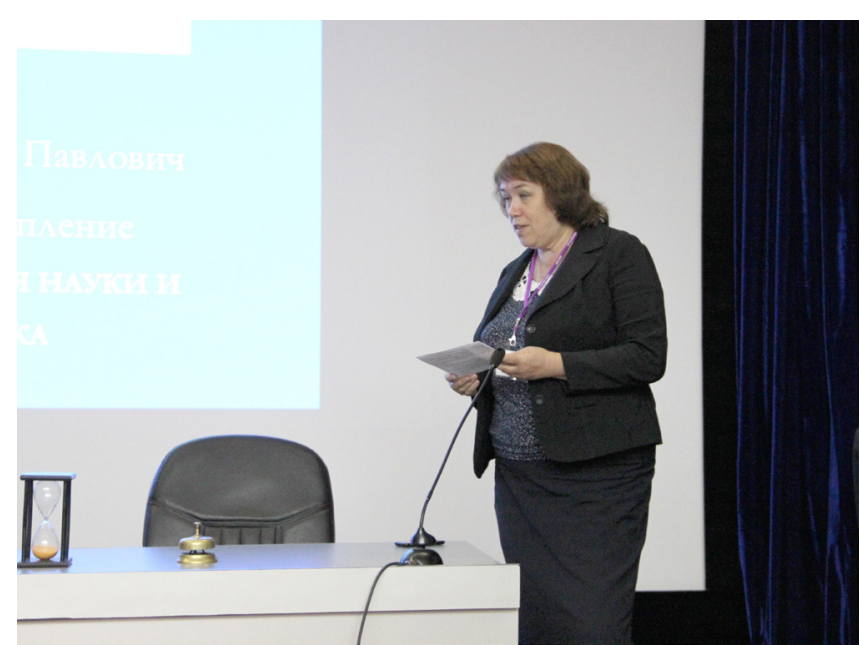

Irina Antonova, ISP SB RAS, Novosibirsk

\section{DAY FOUR. HYBRID MATERIALS BASED ON CARBON NANOPARTICLES}

The last day of the conference began with a plenary session, chaired by Dr Sci. Phys\&Math Irina Veniaminouna Antonova (ISP SB RAS) with the report of Japanese participant in the conference Prof. Yoshiyuki Kawazoe from University Tohoku, Sendai, Japan - "The new carbon allotropes - theoretically predicted and confirmed." Presented penta-graphene 2D-metastable allotrope of carbon consisting of carbon pentagons. Calculations show that pentagraphene is not only dynamic and mechanically stable, but also can withstand temperatures up to $1000 \mathrm{~K}$. It has an unusual negative Poisson's ratio and its ultra-high strength superior graphene. Furthermore, unlike graphite which must be functionalized for open of the gap, pentagraphene has an inherent quasi-direct bandgap width up of $3.25 \mathrm{eV}$, like of $\mathrm{ZnO}$ and $\mathrm{GaN}$. It is equally important that the penta-graph can

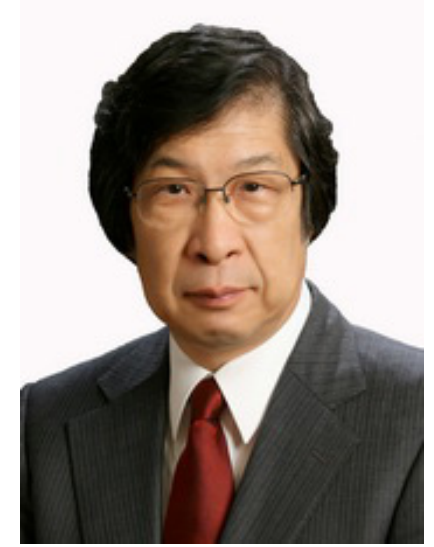

Yoshiynki Kawazoe, Tohoku University, Sendai, Japan 
be exfoliated from the T12-carbon. Wrapped, it may form a nanotube-based pentagon, which are semiconductor regardless of their chirality. Versatility of penta-graphene and its derivatives, is expected to have wide applications in nanoelectronics and nanomechanics.

In the discussion prof. Y.Kawazoe was assisted by Dr Sci. Phys\&Math, prof. Rodion Belosludov, Tohoku University, Sendai, Japan.

Dr Sci. Phys\&Math, prof. Vladimir Fedorov from NIIC SB RAS presented report "The renaissance of low-dimensional materials: from graphene to other layered structures". The discovery of graphene triggered a sharp increase in attention to related it layered and low-dimensional structures, which already in the 70 s there took place due to the hightemperature superconductivity. In Novosibirsk, low-dimensional theme developing for many years, so here holding our conference - the first in Russia on graphene, it seems natural. The report presents the results of experiments with transition-metal dichalcogenides of groups 4-6 of the periodic table. Used method hightemperature cleavage in vacuo bulk crystals when ultrasonic treatment, obtained colloidal dispersion and thin films (after filtration) and di- and three-chalcogenides Mo, Ta, Nb - littlelayer (1 micron) monocrystals lateral size up to $5 \mathrm{~mm}$ (monolayers - for the time being not more than $5 \mu$ ) which lie on a textured substrate. We received several composites with $\mathrm{Pt}$, Au, etc. Investigated their electrical properties,

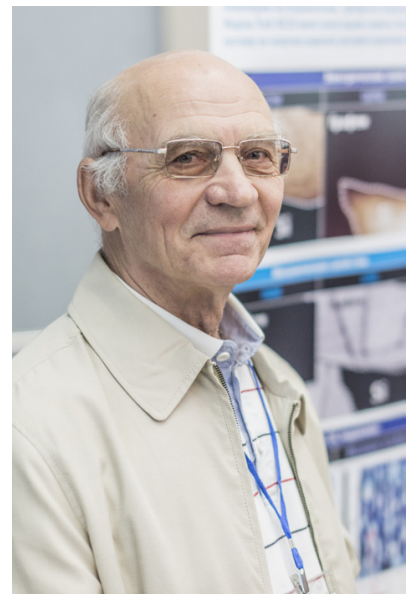

Vladimir Fedorov, NIIC SB RAS, Novosibirsk



Vladimir Kusmetsov, Boreskov Institute of Catabysis SB R AS, Novosibirsk the influence contacts between grains, etc. It's known the possible use of nanostructured chalcogenides in supercapacitors, fuel cells, solar and Li-ion battery, and others.

In the work $\mathrm{PhD}$ Chem Vladimir Kuznetsov from BIC SB RAS with colleagues from NIIC SB RAS and GPI RAS about the structure of real catalytic multiwalled nanotubes (thin $\sim 10 \mathrm{~nm}$ and thick $\sim 20 \mathrm{~nm}$ ) their synthesis was carried out on two types of catalysts. Annealing above the Debye temperature $\left(2800^{\circ} \mathrm{C}\right)$ enlarges defectfree bonds of the tubes, increases resistance to galvanic corrosion and strength. MWCNTs were characterized using HR TM, Raman spectroscopy, measurements of temperature dependence of conductivity (T), magnetoresistance (B) and mechanical properties. It is shown that the properties of CNTs determine the composition of the catalyst, the synthesis conditions, the type of reactor and the conditions of catalyst activation, gas promotion and post-reaction processing.

PhD Chem Olga Podyacheva from BIC SB RAS with colleagues from NIIC SB RAS and

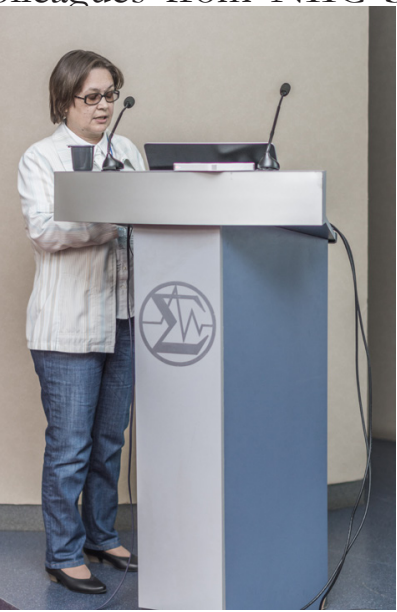

Olga Pod'yacheva, Boreskov Institute of Catabsis SB RAS, Novosibirsk 


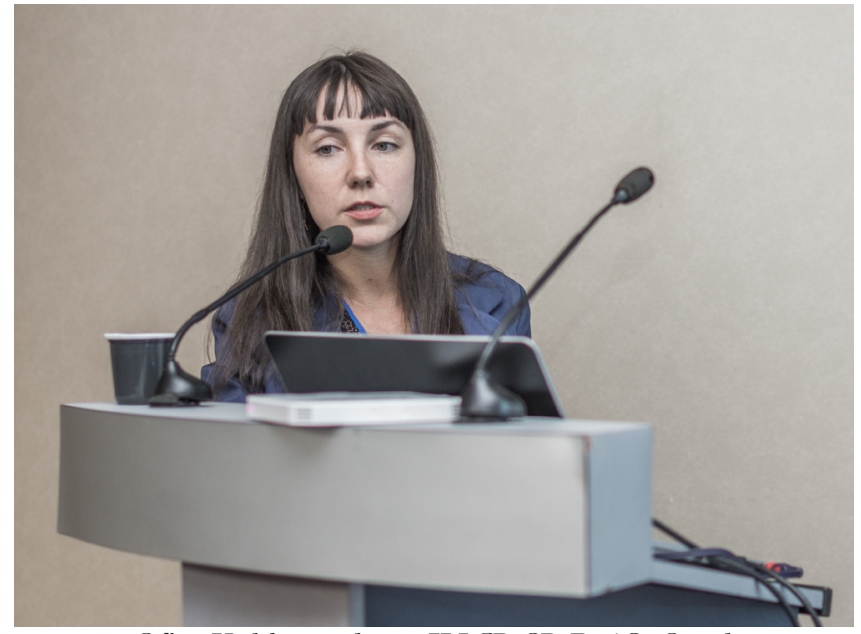

Ol'ga Kokhanovskaya, IHCP SB RAS, Omsk

Kemerovo IUHM in work about nitrogencontaining nanofibers spent catalytic growth $\mathrm{N}$-CNF while the decomposition of ethyleneammonia mixture (with a concentration of ammonia to $75 \mathrm{vol} . \%$ ) on the surface of metal catalysts at temperatures $\geq 550^{\circ} \mathrm{C}$, the duration of the synthesis up to 20 hours and a maximum yield of $70 \mathrm{~g}_{\mathrm{C}} / \mathrm{g}_{\text {cat }}$. Received the N-CNF with coaxial conical packing of graphite layers and a stable defect structure containing up to $8 \mathrm{wt.} \%$ of nitrogen in pyridine like, pyrrole and graphite like states. Obtained the nanocomposites $\mathrm{Pt} / \mathrm{N}$ $\mathrm{CNF}$ with sub-nanometer electron-deficient clusters $\mathrm{Pt}$, wich impart the catalytic properties of the composite.

$\mathrm{PhD}$ Chem Olga Kochanowskaya from Omsk State Technical University and colleagues from IPPU SB RAS in the report about spontaneous decomposition of hydrogen peroxide on the surface of carbon black, the synthesis of which takes place at $>1000^{\circ} \mathrm{C}$, presented the results of the functionalization of its surface during the oxidation of hydrogen peroxide with a co-agents - ozone and singlet oxygen. Defined priority properties of the carbon surface, affecting the kinetic parameter of reaction - the activation energy of the decomposition reaction of $\mathrm{H}_{2} \mathrm{O}_{2}$. The highest degree of oxidation of carbon black is achieved through the grown the carboxyl and lactone groups, using a hydrogen peroxide concentration of $30 \%$ in the liquid phase process and the air enriched with singlet oxygen.

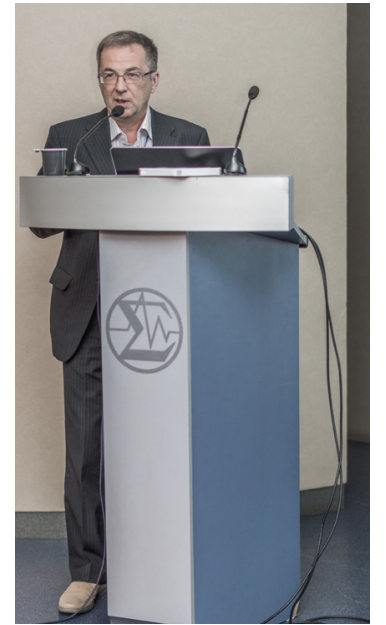

Andrey Basharin, JIHT RAS, Moscow

The conference ended report Dr Sci. Phys\&Math Andrew Basharin from JIHT RAS about growth graphene from carbon vapor: a laser pulse through the window of the chamber with high pressure vaporizes a highly oriented pyrolytic graphite, on which surface from the reverse flow of steam growing graphite (graphene) on the mechanism of vapor-liquidgraphite at a pressure above the triple point of the liquid carbon $p_{0}=10.7 \mathrm{MPa}(4700 \mathrm{~K})$ and the mechanism of steam-graphite at $p<$ $p_{0}$. Surface energy, which determines the size of the critical nucleus in processes of growth, 2 times lower at the border of graphene-liquid carbon compared to the border graphene-vapor. While the dislocation growth from vapor with $p$ above the triple point (11.2 MPa) the layers are atomically smooth, because their ends are wetted by liquid carbon, and at $p$ below the triple point $(9 \mathrm{MPa})$ are rough and covered with secondary vicinals - undulating figures of growth on screw dislocations - due non interlocking of layers, at growing of solid particle condensate in the solid growth stage. The structure of the elementary step of graphite with a width of about $20 \mathrm{~nm}$ and a height of $0.67 \mathrm{~nm}$ step extremely active adsorbs impurities. We investigated also this process in the presence of boron, levitating drop above the superhydrophobic highly porous foam - capillary condensation of liquid carbon on roughnesses of the surface CVD diamond. The study shows such new path of growth of defect-free graphite and graphene. 


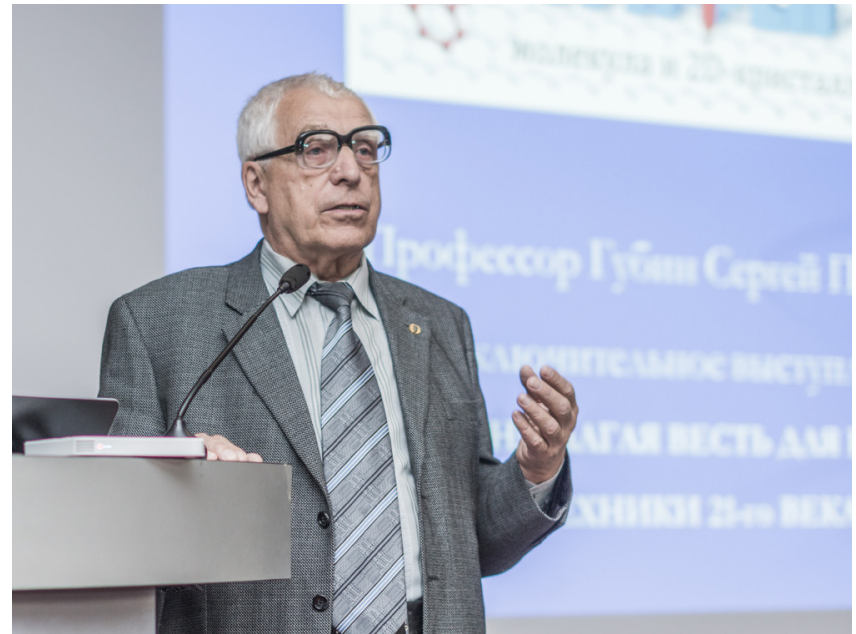

6. CLOSING OF THE CONFERENCE

Chaired in the last day of the conference, Irina Antonova has given the final word Professor SP Gubin.

\section{GUBIN S.P., IGIC RAS, MOSCOW}

We have received here so many new, interesting, factual, theoretical, and any other information, that it should be comprehend. I especially want to thank all the participants. I listened to almost all of the reports and it was very interesting. I want to note that the conference and all reports have been at a good, true a scientific level, reports that participants of the conference were perceived with great interest, there were discussions, debates continued on the sidelines. Poster presentations - I looked through almost all poster presentations - were also very interesting. And so it seems to me that our conference was successful. I think you will agree with this, and let's greet themselves in this regard (applause).

I still want to say that the carbon in all its nano-manifestations, and in particular graphene - is definitely a real future in engineering and technologies for the coming years. I think for the experts, sitting here, this is not necessary to convince. Number of publications on graphene - I talked about this at the beginning - the interest in it in all research teams, according to journals and conferences, are very high. That's because even the conference, for example, that is not related to graphene - on supercritical fluids, held recently in Italy - colleagues have come and say that almost half of the reports were devoted to or associated in varying degrees with graphene. Experts come from another conference and talk about the same thing. Ie graphene is now on the point of interest, and this is extremely important.

There were heard question: what practical result can be here. I would like to answer one important question that arises here. My belief - I wrote in the article published some time ago and possible it looked like some kind of fantasy: the future electronics and information technology, connected exactly with the carbon materials and graphene.

Those who work in the field of classical silicon electronics immediately objected: what you say, into silicon electronics invested trillions of dollars, who is will allow you to replace silicon on some of your graphene? To argue is difficult, on the one hand, on the other hand, simply. Now comes the so-called sixth technological order. Not all - most of those who proclaim it, do not really understand what it is. Honestly, I read a bunch of material on this subject, I can not say that this is deeply understood. But I watched on it from the point of view of the material. After all, we are all material scientists, in one form or another. And I was interested exactly in this aspect of the matter. And of course, the only material that can solve the problems facing the sixth technological order - and there, you know, combination of bio and neuro, and information technologies and so on - is, of course, graphene. Nothing else today in our hands and in humanity no, in order to solve these problems.

As regards the part of this thesis that silicon technology in the electronics works, in it invested billions, the people who are so speculate, I would advise to go to any museum of transport. There are a lot of museums of transport now in different cities, both in our country so and abroad. And look at the exposed beautifully restored, gleaming locomotives. After all, humanity and technology of the late 19th early 20th century reached the highest perfection in terms of the creation of machines of this type, like a locomotive. There was obtained a high efficiency, there were honed all the details, 
there was a well-designed mechanics, grease, etc, etc. There were plants in the Soviet Union, in Germany, in the United States, which produced tens or hundreds of locomotives. And it seemed that this is the height of perfection, and so always will be.

But then came the age of electricity, came the first suburban electric trains - older people may say, and I can say - the first train, and it was very undignified, even funny - ride on this electric current. And it seemed that everything will be as it was, would locomotives, and we will ride on the passenger and freight trains, which are the well-developed machines.

But it took quite a bit of time the locomotives came to naught. They are not here, they are in museums.

And here the situation is the same. Indeed, today's electronics - a silicon electronics. But I did not invent the term, there is a term in the English language and our literature - post-silicon electronics. The only material from my point of view, post-silicon electronics, is of course, graphene and other nanocarbon materials related or related with graphene. In this sense, we are with you in some way on a knife edge. Indeed this is the future, and it does make sense to research this, because it is important, it is useful and necessary.

There is a seminar in Moscow with the same name "Graphene - a molecule and 2D-crystal". We held 18 meetings, and main professionals working in Moscow, and some visiting colleagues participated in this work. We will continue the work of the Moscow seminar, we will continue to try to cover these problems. Of course, it is not easy - cover everything that is done in our country in this direction. Therefore, I beg you, if you have interesting publications - will take the trouble to click a button and send me. I promise you that these publications will not die, they will classified by category, they will be reported in one form or another to those who will be interested in these issues. In general, any information on this case send out to our seminar
Secondly, those who are not Muscovites - you are after all, coming to Moscow periodically, do not take the trouble to call or write in advance and we can plan the seminar so, to you have arrived and presented their new results in this seminar.

Colleagues assure me that it will be necessary to hold the next conference, if not next year, then after two. Well, let's see ...

Once again I want to thank you for activity, for participation in the conference, for their interest in this very interesting, from my point of view, material. Thank you.

\section{OKOTRUB A.V., INSTITUTE OF INORGANIC CHEMISTRY SB RAS, NOVOSIBIRSK}

It was announced, at our conference 150 people. Skeptics said that there will be no more than 70 . Nevertheless, skeptics confounded. To us only arrived 80 people, 20 people registered from Novosibirsk, 20-30 people regularly attended as unregistered. Therefore, the conference was almost always more than 100 people. And I believe that for our Russian level is a very good representation. We have received 53 oral presentations, over 60 poster presentations. Participants represent 20 cities, and as it is surprisingly, from 7 countries. Colleagues came from the United States, Britain, Japan, Germany, Kazakhstan, and Belarus of course.

Topics that we have covered in the course of conference reflect almost all areas of modern studies of graphene. Of course, I would like more good, interesting, original researches that are ahead of the rest. Nevertheless, the overall level indicates

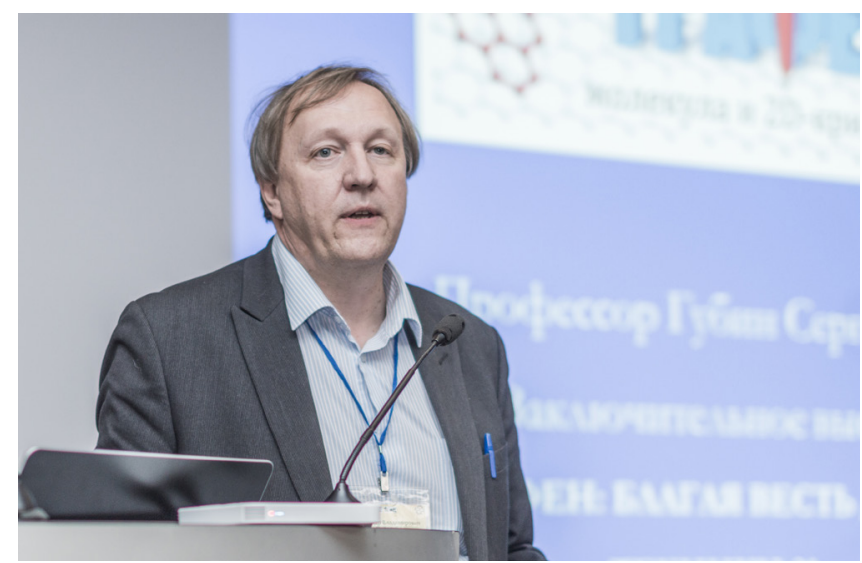


that a graphene-carbon science alive, it is more or less developing. And it seems to me that such an event that's when we all met, talked, found some common ground, have found each other and again envisage any future work is a very important for the future, for the future development. We must use the strengths of the individual laboratories, individual areas and try to move on.

I think that it, of course, is not the limit of our scientific activity, we must continue. There was a proposal to hold the next conference via year in Chernogolovka. We are ready to share all organizational experience, addresses, letters, how best to hold the conference.

We thought that the conference should have a minimum registration fee. And we went down that road. Especially to reduce the registration fee for the young participants. I am grateful to all the sponsors who came to us, who provided funds. Their participation has allowed, on the one hand, to hold our scientific conference, on the other hand, was a very interesting exhibition. Because we now have commercial organizations that work in the field of carbon and they are interested come here. And I think it there was a mutual interest.

\section{***}

It should be noted also an excellent organizational work of a remarkable team of staff and graduate laboratory AV Okotrub, headed by Ph.D.Phys\&Math Fedoseeva Yulia Vladimirovna - the scientific secretary of the conference and her comrades - Viktor Koroteev, Mikhail Katkov, Mikhail Kanygin, Dmitry Gorodetsky, Yegor Lobyak, Olga Sedelnikova, Ekaterina Fedorovskaya, Svetlana Stolyarova, Olga Gurova and Irina Kuznetsova. A significant contribution to this work made Irina Antonova Veniaminovna (ISP SB RAS).

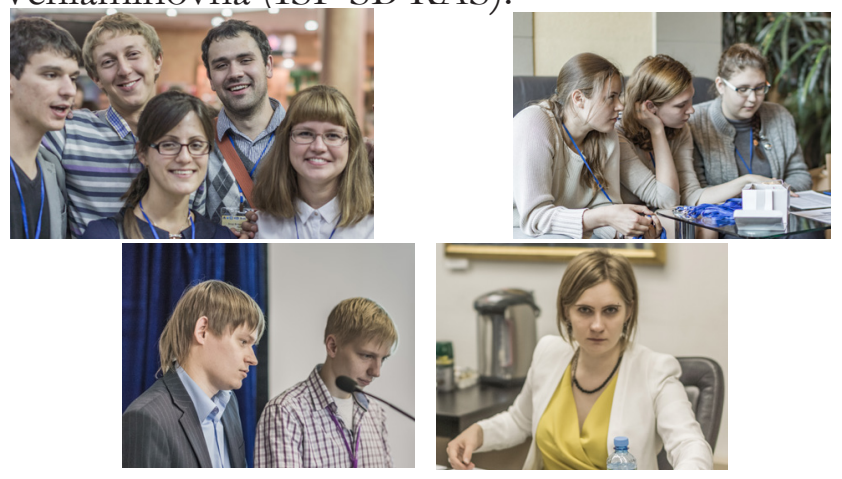

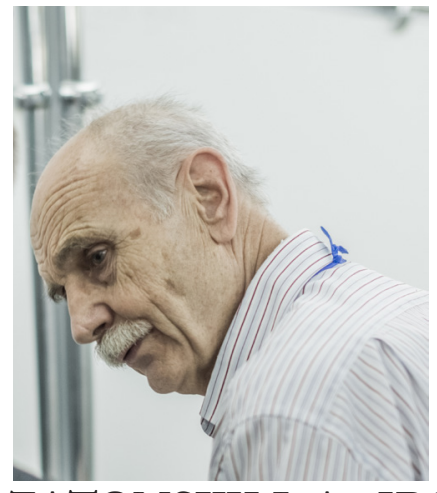

\section{CHERNOZATONSKII L.A., IBCP RAS, MOSCOW}

I certainly shocked in the sense that really all the pointed questions that now exist - I am, in general, too, always look the literature, graphene and not only graphene, near the graphene, and generally on carbon materials - were here very interesting to have been delivered, and the presentations were wonderful. And debates were tightened time, but this is a must for all of us - to discuss each report. I noticed - for each report to follow questions, for each. That's great.

\section{RYCHAGOV A.Yu., IPCE RAS, MOSCOW}

Level conference very high, most importantly - a very high level of organization, I was just amazed. On the Eurasian conferences I have not seen yet so comfortably, efficiently formed, organized enterprises.

I think that is not entirely unequivocal Chernogolovka as option in terms of the second conference. Akademgorodok - a specially created space for conferences but Chernogolovka science city ...

For the future of the conference organizing committee, I would advise to arrange a diploma for youth participants. My experience tells me that it - good for them help.

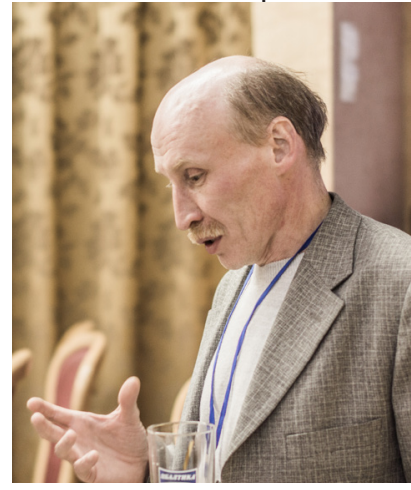


NANOSYSTEMS

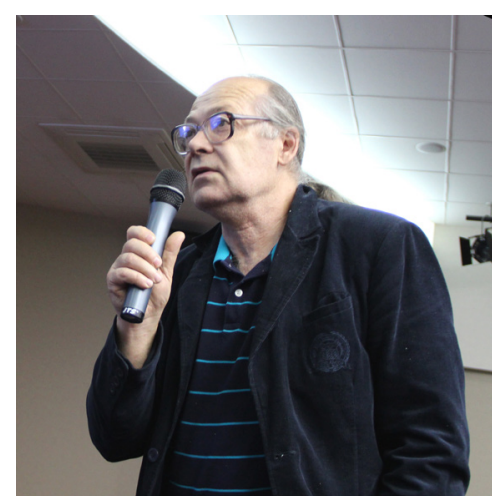

DULIN M.N., IT SB RAS, Novosibirsk

I'm sorry that our there was very little at this conference, even though we have people who deal with this problem.

I wanted to say the following: in addition to the fact that this conference was very interesting - and I have something to compare, is now taking place in parallel, just now have been completed, Lavrentyev Readings on thermodynamics in the IG SB RAS - here are much more interesting than there. Well, for their own reasons.

In concluding remarks, I would just like to note one aspect. Do not consider me a dreamer, but there is a opinion that graphene is a unique situation for the study of space as such, of its fundamental properties. What I mean?

Yet Poincare at the time showed that electromagnetic interaction can exist only in three-dimensional space. Accordingly, if the space is one-dimensional or two-dimensional - inside it the electromagnetic field as such can not be.

But on the border the bound states of photons, of course, exist. And all what we see from the properties of graphene - this is properties such these bound states.

Thank you, it was very interesting to listen to the wonderful reports of conference
FIRST RUSSIAN CONFERENCE "GRAPHENE MOLECULE AND 2D-CRYSTAL" (Novosibirsk, 8-12.09.2015)

After the last session were organized a tours to the three institutions - IFP, IIC and BIC than the participants did not fail to take advantage.

After that was an unforgettable banquet on the shore of the Ob Sea.
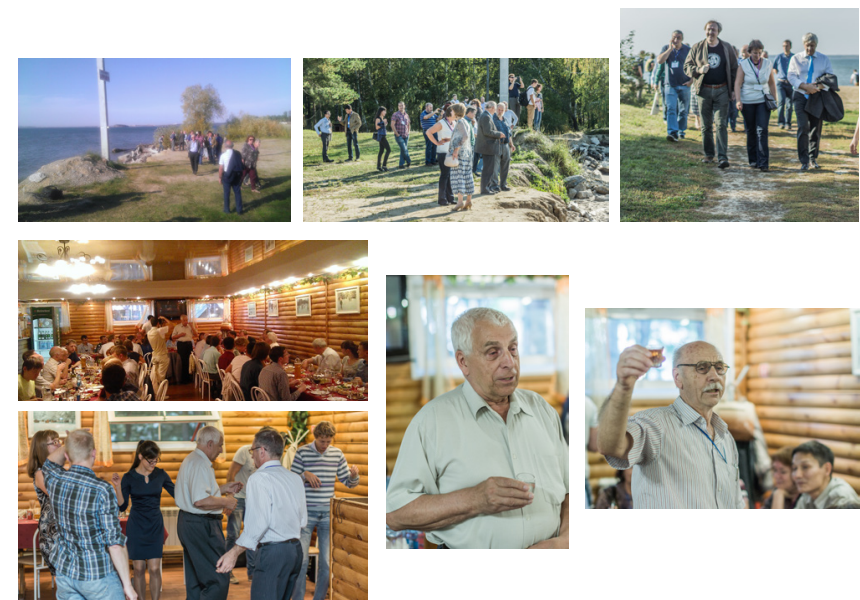

\section{ACKNOWLEDGMENTS}

Author inordinately grateful to Dmitry Pinakov, Andrei Polyakov and Sergey Tkachev - authors photo and video, which visualized process and spirit of the First Russian conference on graphene.

\section{REFERENCES}

1. Gubin Sergey Pavlovich - 50 years in science. RENSIT, 2012, 4 (2):4-5.

2. Okotrub AV. Report RFBR project 15-03-020389 organization of the first Russian conference "Graphene: a molecule and 2D-crystal".

3. Pinakov DV. https://cloud.mail.ru/public/ Geko/C1hVnX1go.

4. Polyakov AV. https://drive.google.com/file/ d/0B9N_ZwpvBztSTkhxOW5seU1UeVk; https://drive.google.com/file/d/0B9N_Zwpv BztSeEQ4MGhRSUdWbWM.

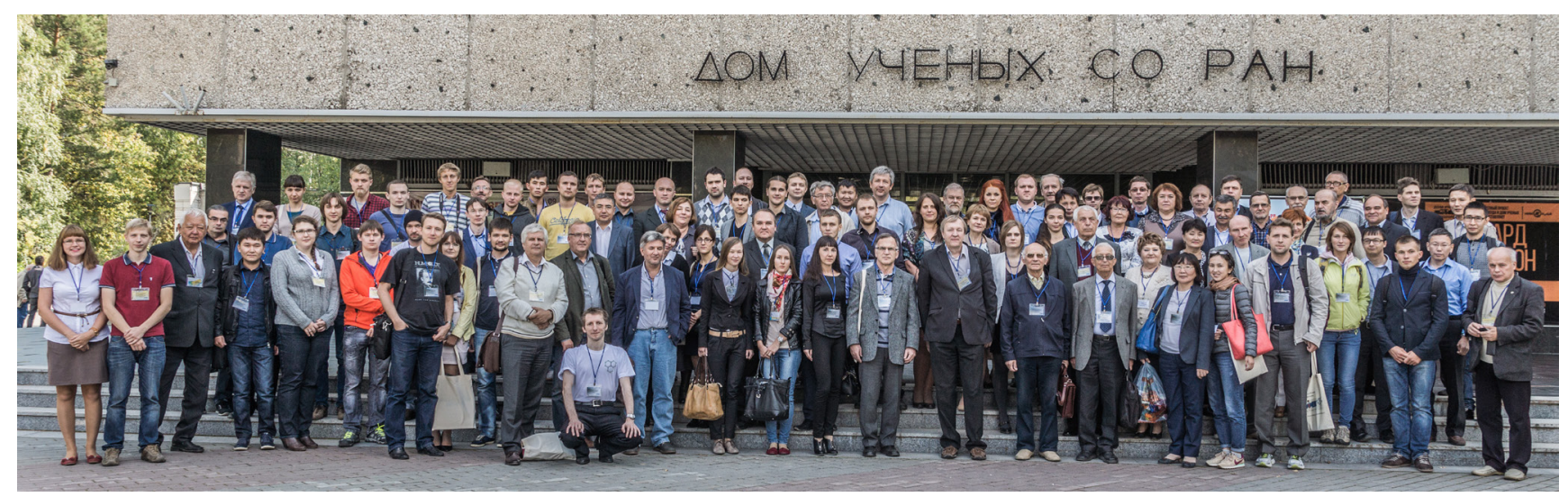




\section{FIRST RUSSIAN CONFERENCE "GRAPHENE - MOLECULE AND 2D-CRYSTAL" (Novosibirsk, 8-12.09.2015)}

\section{Vladimir I. Grachev}

Kotel'nikov Institute of Radio Engineering and Electronics, Russian Academy of Sciences, http://www.cplire.ru 11/7, Mokhovaya str., 125009 Moscow, Russian Federation

grachev@cplire.ru

Abstract. The information about the first Russian conference on graphene "Graphene - a molecule and 2D-crystal", held September 8-12, 2015 in Novosibirsk (Russia), which "grew" from the workshop of the same name, from 2013 held in Moscow under the leadership of SP Gubin is presented. Presented at the conference works conventionally been divided into five research areas: synthesis of graphene and related structures, theoretical methods attached to graphene materials, diagnostics of graphene and related structures, materials and devices based on graphene and related structures, hybrid materials based on carbon nanoparticles. The conference was attended by about 150 people from more than 20 institutes of the Russian Academy of Sciences and more than 10 universities in Russia and countries of near and far (the US, Britain, Germany, Japan, Kazakhstan, Belarus) countries. Having heard and discussed 50 papers and 60 posters. The conference was held in a warm atmosphere of the discussion on a high, according to the participants, the scientific level and with the universal desire to turn it into a permanent Russian conference on graphene.

Keywords: conference, graphene, molecules, crystals, synthesis, diagnostics, graphene structures, hybrid materials

PACS: 01.10.Fv, 51.05.ue

Bibliography -4 references 